\title{
Indoor environment quality and work performance in "green" office buildings in the Middle East
}

\author{
Rana Elnaklah $^{1,2}(\varangle)$, Daniel Fosas' ${ }^{1}$, Sukumar Natarajan' \\ 1. Department of Architecture and Civil Engineering, University of Bath, BA2 7AU, Bath, UK \\ 2. Faculty of Architecture and design, Al-Ahliyya Amman University, Amman, Jordan
}

\begin{abstract}
Globally, a primary concern is whether green office buildings perform as promised in terms of providing better indoor environment quality (IEQ) for employees, which may affect their satisfaction and work performance. In the Middle East, although there has been renewed interest in green building design, post occupancy evaluation of performance has never been conducted to-date, and evidence of actual occupant perception in green and non-green buildings is still ambiguous. Hence, we present the first study on IEQ performance in the Middle East. We show that Jordan can be taken as a representative example and systematically compare five "green" office buildings (representing $71 \%$ of all green-certified office buildings) against eight comparable conventional office buildings (CBs). Detailed bi-lingual survey data on perceived IEQ $(n=502)$ and work performance are accompanied by high-resolution continuous physical measurements of air temperature + relative humidity $(n=83)$ and $\mathrm{CO}_{2}$ concentrations $(n=21)$ with periodic measurements of mean radiant temperature and air speed, covering two typical summers and one typical winter. Results show both buildings types comply with design standards for indoor $\mathrm{CO}_{2}$ levels, while thermal comfort in green buildings is better than in CBs. However, CBs have a higher overall occupant satisfaction of IEQ. Work performance measured as absolute and relative absenteeism was slightly higher in CBs, with no significant differences in relative and absolute presenteeism between the two buildings types. These findings challenge the notion that green buildings improve occupant satisfaction and work performance over CBs and suggest the need for a better understanding of the performance-satisfaction gap.
\end{abstract}

\section{Keywords}

indoor environment quality, green buildings,

POE, work performance, Jordan

\section{Article History}

Received: 07 December 2019

Revised: 14 July 2020

Accepted: 19 July 2020

(c) The Author(s) 2020

\section{Introduction}

Buildings consume $48 \%$ of global energy, and they are responsible for a quarter of global carbon emissions (IEA 2019). The desire to reduce their energy use and greenhouse gas emissions has resulted in an increasing interest in "green buildings" (IEA 2013). Although there is no formal definition of this term, a "green building" conventionally refers to a building that is designed to be efficient in the consumption of natural resources, while conserving energy, reducing harmful impact on the environment, and improving quality of life for users (EPA 2019). This resulted in the creation of several building design standards all over the world, but of which the earliest, i.e. BREEAM (Building Research Establishment Environmental Assessment Method) established in 1990 in the United Kingdom (BREEAM 2019), and LEED (Leadership in Energy and Environmental Design) launched in 1998 in the United States (USGBC 2019), are the most widespread, being used in 70 and 162 countries respectively. These standards cover the design, construction, delivery and operation of buildings, and they are used to evaluate the potential of a building to be energy efficient, with reduced environmental impact, and the ability to provide an adequate indoor environment for users (Wei et al. 2015).

Although most green building standards are applicable to a range of building types, e.g. schools, residential, healthcare and offices, it is the last of these that has seen the greatest adoption. For example, office buildings are the largest single category of LEED buildings globally, representing

E-mail: rade20@bath.ac.uk; ranaelnaklah@gmail.com 
$41 \%$ of LEED stock (USGBC 2019). According to the World Green Building Council (WGBC) three factors, apart from their reduced environmental impact, have driven demand for the construction of green offices: (i) investors and stakeholders recognising the potential for reduced operational costs through a reduction in building energy demand; (ii) reputational benefit through association with positive "green" branding and (iii) improved employee satisfaction and work performance ${ }^{1}$ through improved indoor environment quality (IEQ) (WGBC 2016).

Since IEQ plays an important role for both companies and their occupants, it is worth investigating it in detail. IEQ is defined as "the quality of a building's environment in relation to the health and wellbeing of those who occupy space within it" (CDC 2020). It refers mainly to four parameters, namely indoor air quality (IAQ) and thermal, visual and acoustic comfort (ISO 17772-1 2017). These aspects have a direct effect on the occupant comfort, health, and wellbeing. In addition, according to the WGBC, other secondary physical factors of indoor environment (e.g. layout, aesthetics, amenities, and biophilia) could also play a role in the occupant comfort and satisfaction (WGBC 2016).

As a result of the climate change agenda, there have been international efforts like the Kyoto Protocol (UNFCCC 1998) or the Energy Performance of Buildings Directive (EPBD) in the European Union (European Parliament 2010, 2018), to link the high level of energy performance with the high level of IEQ in buildings. Further, there is growing recognition that the savings in operational costs from green buildings pale in comparison to the likely improvements in work performance emerging from factors such as reduced absenteeism and presenteeism. This is because $90 \%$ of the typical operational cost of a business goes towards employee salary and benefits as opposed to only $1 \%$ on the operational energy of the building (WGBC 2017). Moreover, given that employees spend at least $24 \%$ of their time in a typical week at their workplaces and, in many instances, with poor control over the indoor environmental conditions (e.g. space conditioning, lighting, window control), it is clear that improved IEQ could provide a direct pathway for improved occupant satisfaction and work performance.

However, occupant satisfaction is perceptual rather than objective and hence data is needed over several buildings to reduce the effect of aleatory uncertainties. Similarly, work performance is a secondary measure of the effect of the indoor environment and is hence subject to the effect of other confounding factors.

Despite WGBC's reported benefits of improved in IEQ of green buildings, it is unclear whether green office buildings

1 This term is formally defined in Section 2.2 really perform better in terms of IEQ and increase employee satisfaction or work performance (Veitch et al. 2007; Fostervold and Nersveen 2008; Altomonte and Schiavon 2013; Gou et al. 2013; Ravindu et al. 2015; Tham et al. 2015; Sediso and Lee 2016). Some evidence suggests that though green buildings might achieve their energy efficiency targets (WGBC 2016), they may also exhibit unintended consequences that reduce the quality of indoor environment and curtail occupant satisfaction (Yudelson and Meyer 2013). For example, green buildings with airtight envelope and poorly thought out ventilation can end up with poor air quality that might lead to increase the health problems and discomfort between occupants (Leaman and Bordass 2007; Brown and Cole 2009; Armitage et al. 2011; Davies and Oreszczyn 2012; Collinge et al. 2014).

Although standards such as EN ISO 52003-1 (2017) and EPBD (European Parliament 2018) highlight the importance of creating a balance between the high energy performance of buildings and providing a proper IEQ, historically there has been a lower emphasis on IEQ compared to energy and carbon, due to the climate change imperative.

Most green building rating tools include minimum standards for IEQ and some even consider it as a design parameter through which the score of the building can be enhanced. However, when included, IEQ is typically weighted with lower credits compared to other green design aspects such as energy efficiency (Table 1). In a review of 31 global green rating systems, IAQ was found to contribute an average of only $7.5 \%$ of the total score (Wei et al. 2015). For example, LEED rates buildings as either "Certified", "Silver", "Gold" or "Platinum", according to the scores they achieve, where "Certified" represents the lowest possible achievement and "Platinum" the highest. A building achieves LEED "Platinum" if it achieves at least 80 out of the 110 possible points, something attainable without addressing any of the extra IAQ points, such as increasing the ventilation rate $30 \%$ more than the minimum required rate, using low

Table 1 Relative weighting of energy efficiency and IEQ aspects used in two of the most popular global standards (LEED and BREEAM) and in five standards local to the Middle East

\begin{tabular}{cccc}
\hline & Green building & \multicolumn{2}{c}{ Relative weighting (\%) } \\
\cline { 3 - 4 } Country & standard & Energy efficiency & IEQ \\
\hline United States & LEED & $32 \%$ & $14 \%$ \\
United Kingdom & BREEAM & $19 \%$ & $15 \%$ \\
Jordan & JGBG & $39 \%$ & $9 \%$ \\
Qatar & GSAS & $72 \%$ & $42 \%$ \\
United Arab & ESTIDAMA & $44 \%$ & $37 \%$ \\
Emirates & SI 5281 & $40 \%$ & $18 \%$ \\
Israel & GPRS & $25 \%$ & $10 \%$ \\
Egypt & & &
\end{tabular}


volatile organic compound (VOC) painting and furniture, and providing the building with localised sensors of carbon monoxide $(\mathrm{CO})$ and carbon dioxide $\left(\mathrm{CO}_{2}\right)$. In practice, certified projects seem to address the compulsory IEQ aspects plus any other extra points or credits that are cost-effective and easy to apply (Srebric 2010). In addition, Section 6 "IEQ" in the LEED standard requires conducting baseline IAQ testing as part of the IAQ management plan. This should be done twice, one after the construction stage and the other prior to occupation, usually within 30 to 60 days of issuing the certificate (USGBC 2019). Therefore, this does not account for in-use conditions. The lower attention to IEQ compared to other aspects, especially energy efficiency, can be explained by the initial goal of developing the green building rating tools, which was primarily one of lowering building energy demand.

Taking the Middle East as an example, the population grew at an average rate of $1.7 \%$ per year between 1999 and 2019. This was associated with a growth in the energy demand for heating and cooling of $10 \%$ per year, compared to $0.4 \%$ per year in OECD (Organization for Economic Co-operation and Development) countries over the same period (IEA 2019). In response to this, governments in the Middle East produced new building standards geared towards the production of more energy efficient and sustainable buildings. In fact, all but Iraq, Syria, and Yemen in the Middle East now have their own green building standards. However, the adoption of such standards in the Middle East faces three challenges: (i) lack of public awareness of the direct and in-direct benefits of green buildings (Al Horr et al. 2016); (ii) lack of trained/educated green building professionals that may affect design, construction, or follow-up stages, and (iii) investors associate green design features with costly technologies that threatens the profitability of a project (DODGE 2018). Indeed, these issues are shared across the developing world where the most aggressive growth in global building construction is projected to occur over the next 30 years (Gobbi et al. 2016), raising questions around the viability of these standards in the long term. Unfortunately, little research exists on the as-built performance of green buildings in the Middle East, which would aid in improving awareness while either allaying or confirming concerns around their costs. Studies that do exist focus primarily on the residential sector and, unsurprisingly, attempt to assess the energy performance rather than IEQ of the buildings (Hassouneh et al. 2015). No study heretofore has considered the occupants' perception in green buildings in this region in the surveyed literature.

\section{Literature review}

Given the paucity of literature on green buildings and their impact on occupants in the Middle East, we provide an overview of studies from other parts of the world as a means to understand the key issues.

\subsection{Research on IEQ in green office buildings}

As we observed in Section 1, all green rating tools directly address IEQ and hence there is an expectation that green office buildings will provide better IEQ, resulting in increased employee satisfaction and work performance. However, this remains a debated question despite the numerous studies addressing IEQ in green offices (Newsham et al. 2013; Gou et al. 2014; Pei et al. 2015; Ravindu et al. 2015; Tham et al. 2015; MacNaughton et al. 2016; Sediso and Lee 2016). The two most debated IEQ aspects in green office buildings in the literature over the past two decades have been thermal comfort and IAQ. Table 2 groups these studies according to methods and outcomes. From a methodological standpoint, the overall approach used by all these studies can be classed under the umbrella term post occupancy evaluation (POE). There are several methods of undertaking a POE assessment (e.g. TM22 (CIBSE 2019), BUS (2019), BePAD (Oxford Brookes University 2019)) but they will usually consider one or more of three complementary aspects:

Aspect I Subjective assessment of building performance via occupant feedback (questionnaire, focus group or interviews) (ISO 10551 2019);

Aspect II Objective assessment of energy consumption (e.g. via utility bills or detailed measurement) (CEN ISO/TR 52000-2 2017); and

Aspect III Measurements of physical IEQ parameters including: (i) thermal comfort indicators (e.g. air temperature $\left(T_{a}\right)$, mean radiant temperature $\left(T_{r}\right)$, air speed $\left(\mathrm{V}_{\mathrm{a}}\right)$, and relative humidity $\left.(\mathrm{RH})\right)$, (ii) IAQ indicators (e.g. carbon dioxide $\left(\mathrm{CO}_{2}\right)$, carbon monoxide (CO), and other pollutant metrics), (iii) visual comfort, and (iv) acoustic comfort. The as-built performance of the building is then compared to design goals and against occupant feedback to appraise the relative merits of the final building (e.g. EN ISO 7726 2001; ISO 16814 2008; EN ISO 3382-3 2012; ISO 16817 2017).

In terms of outcomes, we group findings with respect to the differential impact green buildings have on occupant satisfaction when compared to conventional buildings or to national benchmarks, when considering thermal comfort and IAQ. For both thermal comfort and IAQ, studies grouped under the label "A" suggest greater occupant satisfaction in green buildings whereas those grouped as " $B$ " and " $C$ " show lower satisfaction or no difference, respectively. 
Table 2 Summary of studies investigating the perception and satisfaction of thermal comfort (TC) and IAQ in green buildings compared to non-green buildings, benchmark or to the scale midpoint

\begin{tabular}{|c|c|c|c|c|c|c|c|c|c|c|}
\hline \multirow[b]{2}{*}{ Study } & \multirow[b]{2}{*}{ Country or region } & \multicolumn{2}{|c|}{ Buildings covered } & \multicolumn{2}{|c|}{ Occupants surveyed } & \multicolumn{2}{|c|}{ Outcome $^{\dagger}$} & \multirow{2}{*}{$\begin{array}{c}\text { POE } \\
\text { methods }^{\ddagger}\end{array}$} & \multicolumn{2}{|c|}{ Statistical metrics } \\
\hline & & Green & Non-green & Green & Non-green & TC & IAQ & & $p$ & $d$ \\
\hline Brown et al. (2010) & Canada & 1 & 1 & 104 & 145 & & A & I & & \\
\hline Thatcher and Milner (2016) & South Africa & 3 & 2 & 211 & 69 & & A & I & • & • \\
\hline Thatcher and Milner (2012) & South Africa & 1 & 1 & 161 & 79 & & A & I & • & \\
\hline Thomas (2010) & Australia & 1 & - & 238 & - & & A & I, II & • & • \\
\hline Tham et al. (2015) & Singapore & 1 & 1 & 32 & 33 & A & A & I, III & • & • \\
\hline Liang et al. (2014) & Taiwan of China & 3 & 2 & 134 & 99 & A & A & I, III & $\bullet$ & \\
\hline Sediso and Lee (2016) & R.O. Korea & 2 & 2 & $222^{*}$ & & A & & I & • & \\
\hline Pei et al. (2015) & Mainland of China & 10 & 42 & 500 & 500 & A & & I, III & • & \\
\hline Gou and Lau. (2013) & Mainland of China & 1 & - & 182 & - & A & & I, III & & \\
\hline Gou et al. (2014) & Mainland of China & 9 & 5 & 774 & 477 & B & & I & $\bullet$ & • \\
\hline Ravindu et al. (2015) & Sri Lanka & 1 & 1 & $70^{*}$ & - & B & B & I, III & $\bullet$ & \\
\hline Paul and Taylor (2008) & Australia & 1 & 2 & 40 & 53 & B & & I & $\bullet$ & \\
\hline Collinge et al. (2014) & USA & 1 & - & 48 & - & B & & I, II & • & \\
\hline Altomonte and Schiavon (2013) & Global $^{\mathrm{a}}$ & 65 & 79 & 10,129 & 11,348 & B & $\mathrm{C}$ & $\mathrm{I}$ & $\bullet$ & $\cdot$ \\
\hline Menadue et al. (2014) & South Africa & 4 & 4 & $600^{*}$ & - & $\mathrm{C}$ & & I, III & $\cdot$ & • \\
\hline Leaman and Bordass (2007) & $\mathrm{UK}^{\mathrm{b}}$ & 177 & - & - & - & $\mathrm{C}$ & $\mathrm{C}$ & I & • & - \\
\hline
\end{tabular}

Notes:

${ }^{\dagger}$ Study outcome: $\mathrm{A}=$ higher satisfaction in green buildings, $\mathrm{B}=$ lower satisfaction, and $\mathrm{C}=$ no difference found.

${ }^{\ddagger}$ POE methods covered: I = subjective assessment, II = energy performance, III = IEQ measurement.

${ }^{5}$ Whether studies use inferential statistics in determining outcomes: $p$ indicates use of $p$-value for significance testing and $d$ a generic measure of effect size, most commonly Cohen's $d$.

"These studies do not explicitly provide per group sample sizes.

${ }^{\text {a }}$ Refers to data contained within the Centre of the Built Environment (CBE) database at the University of California, Berkeley, $63 \%$ of which come from industrialised countries.

${ }^{\mathrm{b}}$ Data from the Building Use Studies (BUS).

We observe that although there are fewer studies falling into Group B (i.e. green buildings showing lower satisfaction), this group contains the study with the highest overall sample size (Altomonte and Schiavon 2013) which covers a large number of global buildings. Unfortunately, these results are based primarily on occupant perception (Aspect I) rather than measured IEQ (Aspect III). Indeed, only one study in this group uses an Aspect III measurement and control group (i.e. non-green buildings) (Ravindu et al. 2015).

Similarly, only three out of the nine studies in Group A (i.e. green buildings showing higher satisfaction) contain a control group as well as Aspect III measurements. In these studies, a strong alignment was observed between measured and perceived IEQ, suggesting that coincident Aspect III measurements are needed for a holistic assessment of performance.

A key deficiency of the published literature, in general, is the broad reliance on $p$-values for significance testing (14 out of 16) but the lack of accompanying analysis of effect size (7 out of 13). It is well-known that a lack of expression of effect sizes can lead to erroneous conclusions about true significance (for example, a $t$-test suggesting significant difference in mean indoor operative temperatures when the difference is $0.1{ }^{\circ} \mathrm{C}$ ). Finally, although a small number of developing countries (Sri Lanka, South Africa, and China) are represented in these studies, responses are heavily weighted towards industrialised countries. Indeed, the Middle East is currently unrepresented, supporting the case for studies in this region.

\subsection{Work performance and IEQ}

In the literature, "work performance" is also termed "job performance", "productivity", "employee performance", and "individual work performance". Here we use "work performance" as it is the most commonly used term. Work performance can be defined as a measure indicating how an employee is performing against the expected work tasks (Christiansen and Chandan 2017). It has been argued that level of work performance can vary according to the level of comfort with IEQ of workplace (Ali et al. 2015). Employees who are more satisfied with the conditions of their physical workplace are more motivated and achieve a better work performance (Leaman 1995; Dole and Schroeder 2001).

To test this, several studies have attempted to correlate work performance with different IEQ aspects, unfortunately, results across studies are contradictory (Table 3 ). Of the thirteen studies reviewed here, six studies focused on the 
Table 3 Summary of studies investigating the relationship between IEQ aspects and work performance in workplaces

\begin{tabular}{|c|c|c|c|c|c|}
\hline Study & IEQ parameter & Work performance metrics & $\begin{array}{l}\text { Sample } \\
\text { size }\end{array}$ & Study type & $\begin{array}{c}\text { Study } \\
\text { conclusion } \dagger\end{array}$ \\
\hline Singh et al. (2010) & Overall all IEQ & Perceived absenteeism and work hours & 263 & Field & A \\
\hline Tanabe et al. (2015) & Thermal satisfaction & $\begin{array}{l}\text { Simulated office work: three-digit multiplication, } \\
\text { proof reading, and creative thinking }\end{array}$ & 11 & $\begin{array}{l}\text { Field and } \\
\text { laboratory }\end{array}$ & A \\
\hline Lan and Lian (2009) & Indoor air temperature & Computerized neurobehavioral tests & 21 & Laboratory & A \\
\hline Hedge et al. (2005) & $\begin{array}{l}\text { Air temperature and relative } \\
\text { humidity }\end{array}$ & $\begin{array}{l}\text { Software estimated percentage of total keystrokes } \\
\text { (correct + error keystrokes) }\end{array}$ & 9 & Field & A \\
\hline Witterseh et al. (2004) & Noise & Self-estimated performance & 30 & Laboratory & A \\
\hline Wargocki et al. (1999) & Air quality & Simulated office work & 58 & Laboratory & A \\
\hline Milton et al. (2000) & $\begin{array}{l}\text { Lower levels of outdoor air } \\
\text { supply and IEQ complaints }\end{array}$ & Short term sick leave & 600 & Field & A \\
\hline Nishihara et al. (2002) & Thermal conditions & $\begin{array}{l}\text { Computer tasks (Walter Reed Performance } \\
\text { Assessment Battery test) }\end{array}$ & 40 & Laboratory & B \\
\hline $\begin{array}{l}\text { Fostervold and } \\
\text { Nersveen (2008) }\end{array}$ & $\begin{array}{l}\text { Type of lighting (direct or } \\
\text { indirect) }\end{array}$ & The Digit Symbol subtest (WAIS-R) & 64 & Field & B \\
\hline de Korte et al. (2015) & $\begin{array}{l}\text { Control over lighting and air } \\
\text { temperature }\end{array}$ & Standard reading task & 20 & Laboratory & B \\
\hline $\begin{array}{l}\text { de Kort and Smolders } \\
\qquad(2010)\end{array}$ & Dynamic lighting & Days of sick leave & 140 & Field & B \\
\hline Maula et al. (2016) & Air temperature & $\begin{array}{l}\text { Working memory, psychomotor performance } \\
\text { during writing, and long-term memory }\end{array}$ & 33 & Laboratory & B \\
\hline Federspiel et al. (2004) & Ventilation rate & Talk tasks (length of call time) & 119 & Field & B \\
\hline
\end{tabular}

${ }^{\dagger}$ Study outcome: $\mathrm{A}=$ there was an effect and $\mathrm{B}=$ no effect was detected.

effect of indoor air temperature on work performance (Nishihara et al. 2002; Tanabe et al. 2015; Lan and Lian 2009; de Korte et al. 2015; Maula et al. 2016; Hedge et al. 2005); three studied the effect of IAQ, ventilation and $\mathrm{CO}_{2}$ levels (Wargocki et al. 1999; Federspiel et al. 2004; Milton et al. 2000), and one study investigated the link between occupant comfort of overall IEQ and work performance metrics, such as absenteeism (Singh et al. 2010). Some also cover other IEQ aspects such as noise (Witterseh et al. 2004), lighting (Fostervold and Nersveen 2008; de Kort and Smolders 2010) and control over workplace features (de Korte et al. 2015).

As there is no single metric to assess work performance, the studies use a variety of subjective metrics (e.g. occupant satisfaction, self-appraisal), objective metrics (e.g. computerised tests) and secondary indicators (e.g. absenteeism and presenteeism). The studies in Table 3 are categorized into two groups according to their outcomes. Group A suggests a link between the investigated IEQ aspect and chosen work performance metric, while group B indicates no link. Outcomes are split across the two groups almost equally, though overall sample sizes in Group A are somewhat higher. Six out of the thirteen reviewed studies are laboratory based (one additional study uses both laboratory and field data) and typically use computerised tests, often in controlled climate chambers over short periods (hours, or $<5$ days), with small sample sizes (typically 20-60).
Such studies can provide useful primary evidence through careful experimental design and allow for precise control of confounding and independent variables. This allows a cause and effect relationship to be established. However, the outcomes were contradictory in these studies as well, as only three out of six studies showed a link between work performance and IEQ aspects. Four out of the seven field studies use self-reported subjective metrics to measure work performance, while the remaining three use secondary objective metrics (e.g. absenteeism, tardiness) to measure work performance, but usually over short time periods ( $<14$ days/month).

In field studies, both subjective and objective data each have their limitations. For example, it is well-known that self-reported work performance is often inflated (Hoorens 1993). Similarly, absenteeism as a secondary measure may mask the effect of other factors. For this reason, where possible, combined subjective and objective metrics are likely to provide a fuller picture of the effect of IEQ on work performance. Unfortunately, none of the studies in the literature use both metrics. Where time is a factor, i.e., there is an expectation that IEQ may change over time or it is necessary to observe temporal effects, work performance should be evaluated for a period long enough to detect changes in relation to changing IEQ; one month, at least, according to Kessler et al. (2007). 


\subsection{Aim of the research}

The preceding review suggests that (i) the Middle East is unrepresented in the literature on green buildings despite their importance as depicted by the marked growth in energy consumption, (ii) existing research on the impact of IEQ on occupants in relation to green buildings is contradictory and relies primarily on subjective evaluation and (iii) there is insufficient field-data on work performance in relation to IEQ covering both subjective and objective metrics. To address these, we choose:

(1) Jordan as a relevant example of the Middle East, e.g. the building sector represents approximately $33 \%$ of the total energy consumption in the country (Komendantova et al. 2017), which is comparable to the rest of the Middle East at 28\% (Nematollahi et al. 2016).

(2) LEED as the standard representing "green buildings" in Jordan. To-date there are 21 registered $^{2}$ office buildings and 7 certified office buildings in the country, all adhering to the LEED standard (JGBC 2018).

We then perform a systematic field-evaluation of all certified LEED office buildings in Jordan, using comparable conventional "non-green" offices as control, to address the following research questions:

RQ 1. Do LEED office buildings in Jordan achieve the specified minimum IEQ standards in terms of thermal conditions and indoor air quality, after hand over?

RQ 2. Are employees of LEED office buildings in Jordan more satisfied with the quality of their indoor environment compared to employees in conventional offices, and do these correspond with the observed differences in IEQ, if any?

RQ 3. Do employees in LEED office buildings in Jordan demonstrate better work performance compared to employees in conventional buildings, when measured using both subjective and objective metrics?

\section{Methods}

Of the three methodological aspects discussed in Section 2.1, this study uses Aspects I and III to answer the research questions. Aspect I, i.e. subjective assessment of occupant satisfaction with IEQ and their work performance is supported by in-depth interviews to collect further information of investigated buildings to better understand the context. Absenteeism and presenteeism are also measured as secondary indicators of work performance. Aspect III i.e.

\footnotetext{
${ }^{2}$ A LEED registered building achieves some of LEED requirements withou attaining the minimum required score ( 40 points) to be classified as LEED certified, hence the building can be only registered with USGBC without green certification level.
}

objective assessments, co-incident with Aspect I, covered thermal conditions $\left(T_{\mathrm{a}}, T_{\mathrm{r}}, \mathrm{RH}\right.$, and $\left.V_{\mathrm{a}}\right)$ and indoor $\mathrm{CO}_{2}$ concentration levels as an indicator of IAQ (ASTM D6245-18 2018). We do not use Aspect II because assessment of energy use is not part of our research questions. As our interest is in the potential difference in response of particular metrics (from Aspect I and Aspect III) between two or more groups (i.e. different types of buildings), we use a between-subjects experimental protocol (Miller 1984). The next sections detail building selection, occupant recruitment, methods for objective and subjective data collection, and analysis.

\subsection{Building selection}

The total number of LEED-certified office buildings in Jordan is currently seven. The buildings are owner-occupied and belong to organisations whose overall size is in the fourth quartile (by number of full-time employees) (JGBC 2018). To match these, we targeted organizations with a conventional office building (hereafter referred to as $\mathrm{CB}$ ) located within the same urban context of the LEED buildings, with at least 40 full-time employees with similar job roles to those in LEED buildings. Recruitment of buildings for the study was achieved through an invitation letter, explaining the research idea and objectives, sent to senior management of 33 CBs and all 7 LEED buildings. Five out of the seven LEED buildings agreed to participate $(5: 7,71 \%)$ along with eight CBs $(8: 33,24 \%)$, bringing the total to 13 office buildings. The two remaining LEED buildings cited building security criteria as the key reason for not being able to participate. All buildings are in Amman, north-central Jordan, and they match the same climate conditions, long hot summer and short cold winter. The relative humidity is around $70 \%$ in winter and between 30\% and 40\% in summer (DOS 2016).

A contact person, usually a middle manager, was appointed by each participating organisation to discuss the process of conducting the fieldwork. All eight CBs agreed to surveys being administered to their employees, while only five agreed to conduct on-site measurements. The participating LEED buildings confirmed all the research aspects. The data were collected from these buildings during three data collection campaigns spread over two years between Jul 2017 and Feb 2019 (Figure 1). Details of the participating buildings can be seen in Table 4. All the buildings in our study are classed as "offices" with occupants undertaking similar job roles varying between clerical, design, administrative, and management (Figure 2, Figure 3).

\subsection{Occupant recruitment}

As the maximum number of employees across the 


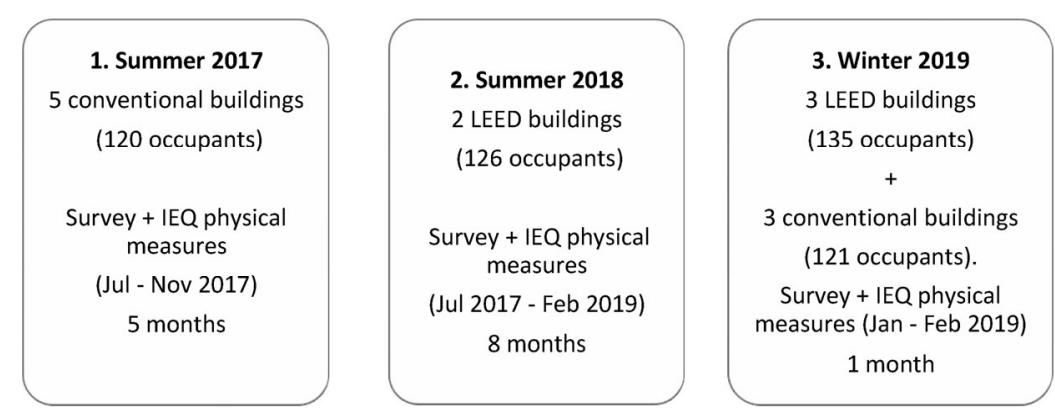

Fig. 1 Overview of research data collection (July 2017-February 2019; $n_{\text {buildings }}=13 ; n_{\text {occupants }}=502$ )

Table 4 Comparison of LEED and conventional building (CB) characteristics

\begin{tabular}{|c|c|c|}
\hline Item & LEED & $\mathrm{CB}$ \\
\hline Construction age range & $2010-2019$ & $2000-2019$ \\
\hline TFA $\left(\mathrm{m}^{2}\right)$ & $\begin{array}{l}9,000-15,000 \mathrm{~m}^{2} \text { (including car parking, gathering areas, } \\
\text { meeting rooms, cafeteria, and sport facilities) } \\
\text { Estimated "office only" TFA range is: } 1650-2000 \mathrm{~m}^{2}\end{array}$ & $700-1500 \mathrm{~m}^{2}$ \\
\hline Workplace layout & $\begin{array}{l}85 \% \text { of respondents work in open-plan workplaces and } \\
\text { only } 15 \% \text { had private offices }\end{array}$ & $\begin{array}{l}56 \% \text { of respondents had open plan workplace and } 44 \% \\
\text { had their own private offices }\end{array}$ \\
\hline Employment area $\left(\mathrm{m}^{2}\right)$ & $\begin{array}{l}4 \mathrm{~m}^{2} / \text { person in open plan } \\
12 \mathrm{~m}^{2} / \text { person in private offices }\end{array}$ & $\begin{array}{l}4 \mathrm{~m}^{2} / \text { person in open plan } \\
10 \mathrm{~m}^{2} / \text { person in private offices }\end{array}$ \\
\hline Total number of employees & $50-120$ & $40-50$ \\
\hline Number of floors & $8-14$ & $2-5$ \\
\hline Ventilation & $\begin{array}{l}\text { Active ventilation systems, designed to achieve } \\
8.5 \mathrm{~L} /(\text { s.person) }\end{array}$ & $\begin{array}{l}\text { Concurrent mixed-mode ventilation (active cooling } \\
\text { between May and October, while active heating during } \\
\text { December, January, and February, buildings natural } \\
\text { ventilation in March, April, and November by open/ } \\
\text { close windows to regulate the internal air temperature }\end{array}$ \\
\hline Lighting & $\begin{array}{l}\text { Artificial and natural lighting (occupancy and illuminance } \\
\text { sensors) }\end{array}$ & $\begin{array}{l}\text { Artificial and natural lighting (occupants have full control } \\
\text { over lighting) }\end{array}$ \\
\hline Windows & Fixed double-glazed facades & Evenly distributed operable windows \\
\hline Other features & $\begin{array}{l}\text { Walls were painted with volatile organic compound }\left(\mathrm{VOC}_{s}\right) \\
\text { free paint and floors covered with carpet to eliminate indoor } \\
\text { air pollutants }\end{array}$ & - \\
\hline LEED certification category & $\begin{array}{l}1 \times \text { LEED-Silver } \\
3 \times \text { LEED-Gold } \\
1 \times \text { LEED-Platinum }\end{array}$ & - \\
\hline
\end{tabular}
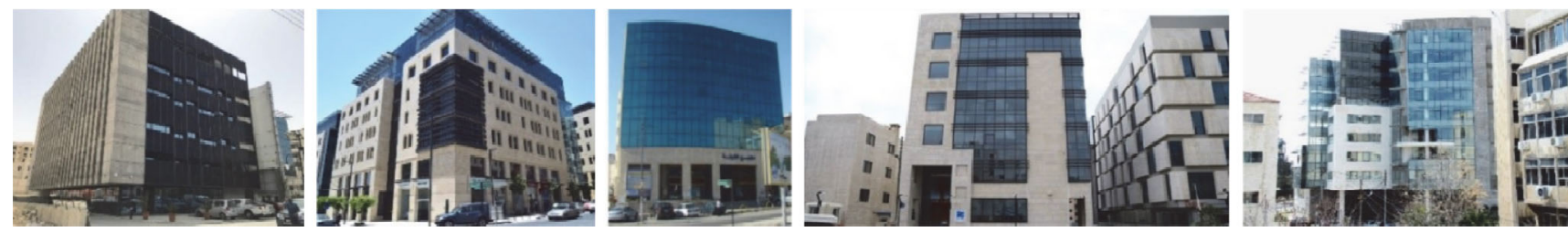

Fig. 2 Examples of buildings in this study

recruited offices was 120, all employees in all organisations were invited to participate in the research through a leaflet that explained the overall aim of the research, data privacy procedures, and the need for prior informed consent. This resulted in an overall return rate of $53.5 \%(241 / 450)$ in CBs and 65.2\% (261/400) in LEED buildings. A complete socio-demographic breakdown split by building type can be seen in Appendix A, which is available in the Electronic Supplementary Material (ESM) in the online version of this paper. We observe that job categories, working experience, daily working hours, education level and monthly earnings are broadly comparable across the building types. However, we observe systematic differences in gender distribution (39\% and 49\% females in CB and LEED, respectively) and 

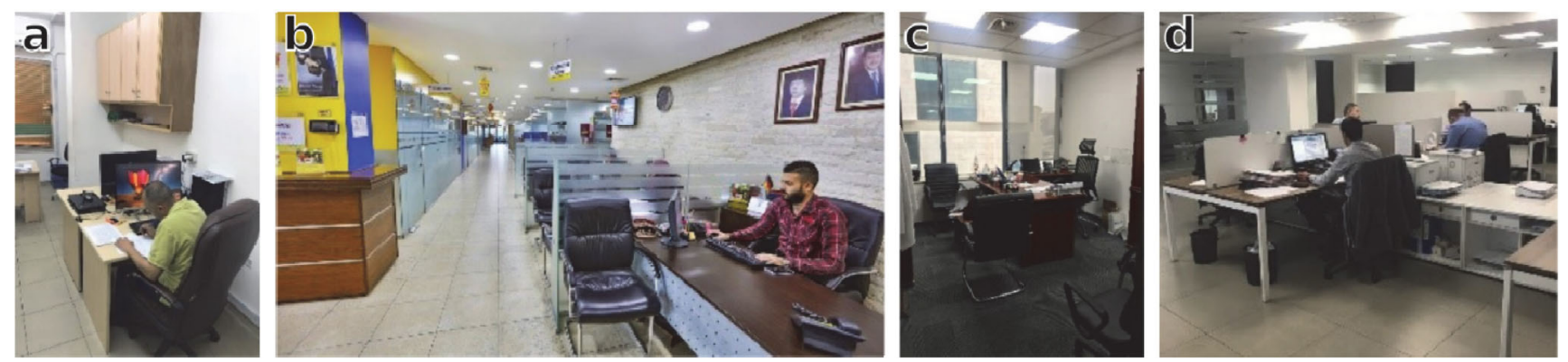

Fig. 3 Selected workplaces in the study (examples a-b from conventional building, $c-d$ from LEED)

the number of people per office (a majority of 1-4 people per office in CB compared to 10-24 in LEED). Both are representative of the respective distributions in each building type, i.e., fewer females and cellular offices in the eight $\mathrm{CB}$ buildings surveyed.

\subsection{Objective measurements}

To address RQ1 and the latter half of RQ2, continuous on-site monitoring of $T_{\mathrm{a}}, \mathrm{RH}$, and $\mathrm{CO}_{2}$ was conducted in the investigated buildings (Table 5) (Elnaklah 2020). Continuous measurements were undertaken using Raspberry$\mathrm{Pi}$-based sensors that have undergone rigorous testing and calibration, making them suitable for obtaining time series with good accuracy (Vellei et al. 2016; Lovett et al. 2016). Monitored buildings were provided with 83 Raspberry-Pi to monitor air temperature and relative humidity, and 21 Raspberry-Pi to monitor $\mathrm{CO}_{2}$ (Figure 4). Indoor sampling positions were selected based on four coverage criteria (i) areas with both high and low density, (ii) areas experiencing any occupant complaints or discomfort, (iii) different floors of the buildings, and (iv) sampling criteria for $\mathrm{CO}_{2}$ concentration is one per $500 \mathrm{~m}^{2}$ for buildings with total floor area less than $3000 \mathrm{~m}^{2}$ (IAQMG 2019).
In LEED buildings, a majority of sensors were located in the open plan workplaces, as these were the most common type of occupied area within the buildings. While in CBs, sensors were located in both open plan workplaces and cellular offices. All sensors were placed on employees' desks at heights varying between 0.70 and $0.90 \mathrm{~m}$ from floor level and away from local heat sources (e.g. heaters, windows, and PC monitors). The date and time were setup according to the local time in Jordan. All sensors were identified with a label showing the serial number and building name. Employees were asked not to cover, touch or unplug the sensors from power. The data were logged at 5-minute intervals and downloaded on a weekly basis during the monitored periods.

In addition to continuous measurements, periodic spot measurements which complied with EN ISO 7730 (2005) and ISO 7726 (2001) were undertaken in the investigated buildings to assist in evaluating the occupants' thermal comfort and calculate the predicted mean vote (PMV) (ANSI/ASHRAE 55 2017; d'Ambrosio Alfano et al. 2020). The spot measurements covered four physical indicators: $T_{\mathrm{a}}, T_{\mathrm{r}}, \mathrm{RH}$, and $V_{\mathrm{a}}$ for which readings were taken simultaneously to the time of the survey using the HD $32.3 \mathrm{kit}$ (Delta OHM 2019). In addition, two other indicators were

Table 5 Number and location of sampling points for continuous monitoring using Raspberry-Pi devices $(\mathrm{F}=$ floor, $\mathrm{CB}=$ conventional building)

\begin{tabular}{|c|c|c|c|c|c|c|}
\hline \multirow[b]{2}{*}{ Building } & \multicolumn{2}{|c|}{ Sensor type } & \multirow[b]{2}{*}{ Location } & \multicolumn{2}{|c|}{ Monitoring period } & \multirow[b]{2}{*}{ Total continuous day } \\
\hline & $T_{\mathrm{a}}+\mathrm{RH}$ & $\mathrm{CO}_{2}$ & & Months & Year/s & \\
\hline LEED1 & 3 & 2 & F2, F3 & \multirow{3}{*}{ Jan - Feb } & \multirow{3}{*}{2019} & \multirow{3}{*}{$30\left(T_{\mathrm{a}}+\mathrm{RH}+\mathrm{CO}_{2}\right)$} \\
\hline LEED2 & 3 & 2 & $\mathrm{~F} 2, \mathrm{~F} 3$ & & & \\
\hline LEED3 & 3 & 2 & $\mathrm{~F} 2, \mathrm{~F} 3$ & & & \\
\hline LEED4 & 5 & 2 & F1, F2, F3 & \multirow{2}{*}{ Jul - Feb } & \multirow{2}{*}{$2018-2019$} & \multirow{2}{*}{$240\left(T_{\mathrm{a}}+\mathrm{RH}+\mathrm{CO}_{2}\right)$} \\
\hline LEED5 & 35 & 3 & F1, F2, F3, F4 & & & \\
\hline $\mathrm{CB} 1$ & 8 & 2 & $\mathrm{~F} 1, \mathrm{~F} 2$ & \multirow{5}{*}{ Jul - Nov } & \multirow{5}{*}{2017} & \multirow{5}{*}{$150\left(T_{\mathrm{a}}+\mathrm{RH}+\mathrm{CO}_{2}\right)$} \\
\hline $\mathrm{CB} 2$ & 8 & 2 & F2, F3 & & & \\
\hline $\mathrm{CB} 3$ & 8 & 2 & $\mathrm{~F} 1, \mathrm{~F} 2$ & & & \\
\hline $\mathrm{CB} 4$ & 5 & 2 & $\mathrm{~F} 1$ & & & \\
\hline CB5 & 5 & 2 & $\mathrm{~F} 1$ & & & \\
\hline
\end{tabular}




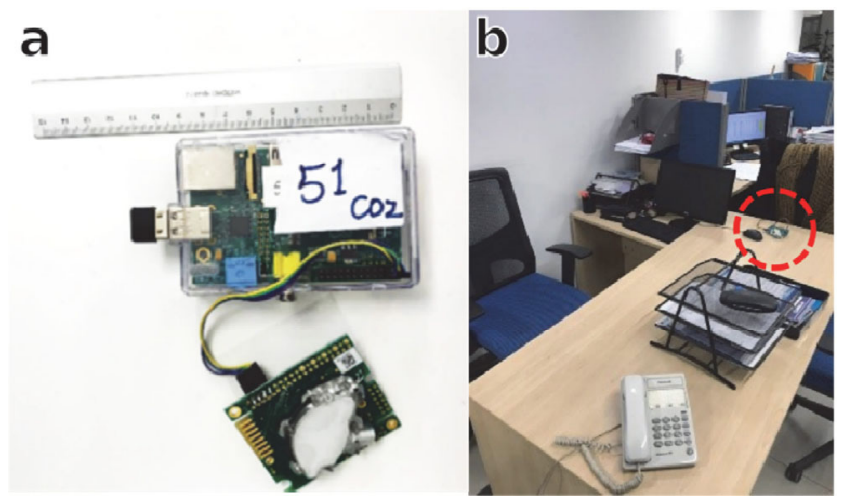

Fig. 4 Raspberry-Pi based $\mathrm{CO}_{2}$ logger in the study (a: logger; b: example of logger location on employee's desk)

assessed to help in calculating the PMV, clothing thermal insulation (clo) and metabolic rate (met). All the investigated buildings in our study are offices and their occupants involved in typical sedentary work activities (e.g. reading, writing, computer typing) with occasional walking between workstations for document delivery or communication. This is expected to entail a light metabolic rate between 1.1 and 1.3 met (EN ISO 8996 2004; ANSI/ASHRAE 55 2017). As the monitoring campaigns were conducted in both summer and winter, occupant clothing insulation levels ranged between 0.9 and 1.4 clo (EN ISO 9920 2007; ANSI/ ASHRAE 55 2017).

Further, local discomfort was assessed during the spot measurements, and no significant local discomfort sources were detected, thus we assume that the Raspberry-Pi devices reflect the actual performance of the building in terms of air temperature and relative humidity. Technical specification of our instruments is provided in the Appendix B, which is available in the Electronic Supplementary Material (ESM) in the online version of this paper.

\subsection{Subjective measurements}

Here, we describe first, the overall process, and then the details and sources used to design the questionnaire to help address RQ2 and RQ3. Initial discussions with the various gatekeepers suggested that the most effective means to obtain high return rates would entail a paper-based questionnaire, completed with researcher assistance.

The questionnaire contained both English and Arabic text, as most participants' first language is Arabic. The English version of the questionnaire was translated into Arabic by a "sworn translator" who has a high level of education and experience. The translated version of the questionnaire was tested before starting the study by sending it to five university students fluent in both Arabic and English. Based on their suggestions, minor refinements such as deletion of overlapping terms were made. The English originals were retained alongside the Arabic translations in the final questionnaire.

Survey respondents were provided with an introductory session (5-7 $\mathrm{min}$ ) by the researcher to explain the research idea and objectives, and that all responses will be anonymised and not directly shared with gatekeepers. Prior informed consent was obtained following well-established university ethics procedures. Pilot tests suggested an average survey completion time of five minutes, which was borne out during data collection.

The questionnaire comprises three sections. The first section contains six socio-demographic questions covering gender, job role, work experience, salary, number of daily working hours and workplace layout. The second and third sections, described below, were designed to evaluate occupant perception of IEQ and work performance respectively.

Occupant satisfaction with IEQ: This section was based on two well-established workplace surveys (WGBC 2017): the Building Use Studies survey (BUS 2019) and the Occupant Indoor Environmental Quality Survey by CBE, Berkley (CBE 2019). Four key IEQ parameters were interrogated: indoor air quality and ventilation, noise, lighting, and thermal comfort, with each aspect covered using 2-5 questions that had three types:

(i) Satisfaction rating of IEQ items on a seven Point-Likert scale going from dissatisfied $(-3)$ to satisfied $(+3)$, where 0 represents a neutral or no opinion.

(ii) Each of the previous questions was followed with a question asking respondents to rate if a particular IEQ aspect affect the work performance negatively on a seven-point scale from "not a significant negative effect" (1) to a "significant negative effect" (7).

(iii) Open-ended question to allow respondents the freedom to provide more detailed responses and raise any specific problem that is not covered in the survey.

In addition, thermal sensation vote (TSV) and thermal preference vote (TPV) of occupants were assessed using the widely used ASHRAE 55 (2017) seven points scale.

Work performance: Based on Singh et al. (2010) and Milton et al. (2000), we use absenteeism and presenteeism as key indicators of work performance. While other, more direct measures, such as computerized neurobehavioral tests, standard reading task, memory task, and different simulated office tasks were adopted in the literature, these were considered inappropriate for our study due to being too intrusive or not repeatable at-scale in a real working environment.

Absenteeism can be defined as the average number of employee days lost per year through illness and unauthorized absences as a percentage of contracted days (IFC 2017). While presenteeism can be defined as being not fully 
functioning at work because of health issues (WGBC 2017). Chua et al. (2016) found in their study that the high level of employee absenteeism could be viewed as an indicator of poor work performance, and the highly motivated and comfortable employees take $37 \%$ fewer sick leaves.

We assess absenteeism and presenteeism using the short version of the Health and Work Performance Questionnaire (WHO HPQ), developed by the World Health Organization (WHO). This questionnaire is well-established in the literature and is considered both valid and reliable (Kessler et al. 2007; Pournik et al. 2012; de Kort and Smolders 2010). For both absenteeism and presenteeism one may use either the preceding 7 days or 4 weeks, but we use both as an intermetric reliability check. The absenteeism section consists of 8 questions covering:

- The total number of working hours in the last 7-day (and the last 4-week) prior to the survey date.

- The number of missed workdays due to illness or other reasons (including vacations).

- Number of days-miss part of working day-due to physical/mental health issues or other reasons.

- Number of days when they came early to work, or went home late, or worked on their day off.

- The expected total working hours by employer in a typical 7-day week.

The monthly Absolute Absenteeism ( $A_{\mathrm{A}}$, hours) is then calculated as (Kessler et al. 2007):

$A_{\mathrm{A}}=4 \times B_{4}-B_{6}$

where $B_{4}$ represents the number of expected working hours by employer in a typical 7-day week, and $B_{6}$ is the number of hours that employee worked in the past 4 weeks. Similarly, monthly relative absenteeism $\left(A_{\mathrm{R}}\right)$ is computed as:

$A_{\mathrm{R}}=\frac{4 \times B_{4}-B_{6}}{4 \times B_{4}}$

where $A_{\mathrm{R}}$ is a percentage ranging between a negative number (i.e. the employee worked more than the expected working hours), 1 (indicates employee was always absent during the last 4 weeks) and 0 (indicates employee work as expected).

Turning to the presenteeism section, it consists of three questions asking employees to evaluate their work performance on a scale from 0 to 10 (where 0 is the worst performance and 10 is the top performance). These ask employees to:

- Rank their work performance according to most workers in a similar job.

- Evaluate their work performance during the last year.

- Evaluate their work performance in the period of 4 weeks prior to the survey date.
In this section, the absolute and relative presenteeism were measured to provide better understanding of employee work performance for 4 weeks. The absolute presenteeism $\left(P_{\mathrm{A}}, \%\right)$ was calculated as:

$P_{\mathrm{A}}=10 \times B_{11}$

where $B_{11}$ is the self-assessed score of work performance in the last 4 weeks. $P_{\mathrm{A}}$ is an integer score between 0 (total lack performance during working hours) and 100 (no lack of performance during working hours). Relative presenteeism $\left(P_{\mathrm{R}}\right)$ is calculated as:

$P_{\mathrm{R}}=\frac{B_{11}}{B_{9}}$

where $B_{9}$ is the self-reported score of work performance compared to other employees working in a similar job. $P_{\mathrm{R}}$ ranges between 0.25 (indicating the employee worked $25 \%$ or less than other workers), and 2 (indicating that the employee worked $200 \%$ more than other workers). For example, if respondent rates his own performance as 1 , and the average worker's performance at 8 , he is assigned a presenteeism score of 0.25 ( 1 divided by 8 is 0.125 , restricted to the lower bound of 0.25 ). This means, that respondents' work performance was as low as one-fourth the average. If another respondent rates his performance at 9, but rates the average worker's performance at 3 , he gets the score of 2 (9 divided by 3 is 3 , restricted to upper bound of 2 ). This means, that respondent has more than twice the work performance of the average worker.

In addition to the questionnaires, 15 semi-structured interviews with the buildings' owners, managers, designers, and operators were conducted between July 2017 and Feb 2019. Each interview took approximately 60-90 min. The data generated by the interviews were documented using handwritten notes. These interviews had three themes:

(1) Motivations to implement green design and basic data (e.g. total floor area of building, building age, total number of employees).

(2) Details of green features (e.g. green certification level, Heating, Ventilation and Air-Conditioning system (HVAC), lighting).

(3) Architectural and structural details.

\subsection{Analysis methods}

Classical hypothesis testing is used to analyse potential differences in the performance of conventional and LEED buildings in the study. When the response variable is numerical and continuous over an interval, like the case of $\mathrm{CO}_{2}$ concentration in part-per-million (ppm), the $t$-test is used to test the null hypothesis that there is no difference in 
the mean response between the two groups, which assumes that samples follow a normal distribution. In particular, Welch's unequal variances $t$-test is used as the number of samples or their variances are not necessarily equal, as seen in the next section. Confidence intervals are reported together with the differences between groups and the effect size is reported using Cohen's $d$ metric,

$d=\frac{\mu_{\mathrm{a}}-\mu_{\mathrm{b}}}{s}$

where $\mu_{\mathrm{a}}$ represents the sample mean in one group, $\mu_{\mathrm{b}}$ the mean of the other sample and $s$ the pooled variance of the samples (Cohen 1988).

Other response variables follow a categorical or ordinal scale, like satisfaction scores on a 7-point Likert item (Garland 1991). For these cases, the non-parametric KruskalWallis $H$ test is used to test the null hypothesis that there is no difference in the median response between the two groups, under the assumption that the samples of the two groups follow the same distribution. Effect sizes are reported using the rank biserial correlation (RBC) (Cureton 1958), a measure of how disaggregated the ranks of two groups $a$ and $b$ are. Values of RBC range between -1 and 1: values of 0 mean that the ranks are similar between the two groups and values of -1 and 1 that the ranks of one group are all below those of the other (the sign depends on which of the two groups is taken as the reference). For thermal comfort data, the TSVs were compared to the ANSI/ASHRAE 55 (2017) comfortable range of $[-1,+1]$, and PMVs were compared to ISO 7730 (2005) comfort range of $[-0.5,+0.5]$, then a comparison between TSVs and PMVs was conducted in both buildings types.

The analysis considers only questionnaires with responses to every question. However, in the case of absenteeism and presenteeism, data were cleaned according to WHO guidelines (Kessler et al. 2007). This section of the questionnaire requires users to give thoughtful numerical responses about their working hours. The standard questions include pre-quest, i.e. questions that are not included in the analysis but that help respondents give better estimates on a following question. The pre-quest allows superficial responses to the hours worked in the last 28 days to be estimated. Aligning with WHO guidelines, a rational imputation of the data is made for large differences between the estimated hours the occupant worked in the last 28 days and the reported ones based on the $90^{\text {th }}$ percentile (Kessler et al. 2007). This reduced the dataset from 502 total responses to 452 (i.e. from 261/241 responses in LEED/CB to 228/224).

The analysis was done using (i) Python (Python Software Foundation 2020), including Numpy (Oliphant 2006; van der Walt et al. 2011), Pandas (McKinney 2010) and Pingouin (Vallat 2018) libraries, and (ii) R (R Core Team 2019), including the Tidyverse family (Wickham et al. 2019) and HH libraries (Heiberger and Robbins 2014).

\section{Results and discussion}

This section presents the results from the objective measures of thermal conditions $\left(T_{\mathrm{a}}, T_{\mathrm{r}}, \mathrm{RH}\right.$, and $\left.V_{\mathrm{a}}\right)$, and IAQ $\left(\mathrm{CO}_{2}\right.$ concentration levels) (see Aspect III in Section 2.1), and the results of subjective measures including occupant satisfaction with IEQ and work performance (absenteeism and presenteeism) (see Aspect I in Section 2.1). As we are interested in occupant perception during working hours, data between 09:00 and 17:00 from Sunday to Thursday were extracted and analysed based on the typical working time in Jordan (Friday and Saturday being the weekend). Thermal comfort conditions and $\mathrm{CO}_{2}$ data were compared to both the recommended standards LEED/ASHRAE 55 (2017) and LEED/ASHRAE 62.1 (2019) respectively, and across building groups.

\subsection{IAQ}

Taking the $\mathrm{CO}_{2}$ concentration as a proxy for indoor air quality, two complementary aspects were studied. Firstly, mean $\mathrm{CO}_{2}$ concentration levels were compared according to the building type, and secondly, the average fraction of the day within the LEED limit of 1100 ppm was appraised (Figure 5) (ANSI/ASHRAE 62.1 2019). For average $\mathrm{CO}_{2}$ concentration levels, Welch's unequal variances $t$-test suggests that the null hypothesis of equal means between CBs $(\mu=587.23, \sigma=219.54, n=3223)$ and LEED $(\mu=$ 655.96, $\sigma=198.67, n=1576)$ buildings can be rejected $\left(t(3421)=-10.87, p\right.$-value $<10^{-4} ; \Delta \mu_{\text {LEED-CB }}=+68.73 ; 95 \% \mathrm{CI}$ [56.33, 81.13]; $d=0.32$ ). Although statistically significant, the effect size is small, and the difference is negligible in practical terms since both means are well under the upper limit of $1100 \mathrm{ppm}$, even though LEED has a marginally higher concentration. This characterization contrasts with the second test for the average fraction of the day within design limits. Here, the test suggests that the null hypothesis of equal means between CBs $(\mu=95.85, \sigma=3.35, n=31)$ and LEED ( $\mu=98.26, \sigma=3.67, n=31)$ buildings, can be rejected $\left(t(60)=-2.71, p\right.$-value $<10^{-2} ; \Delta \mu_{\text {LEED-Св }}=+2.41$; $95 \%$ CI $[0.63,4.20] ; d=0.65)$. These results show how LEED buildings deliver an environment that is more often within the design specification despite the marginally higher $\mathrm{CO}_{2}$ concentration levels, with a moderate effect size. This variation is judged to be attributable to the different design approaches of ventilation in these buildings. LEED buildings are designed to be air-tight to reduce energy consumption and use controlled HVAC systems, while the CBs used mixed-mode ventilation that depends on wind and stack 

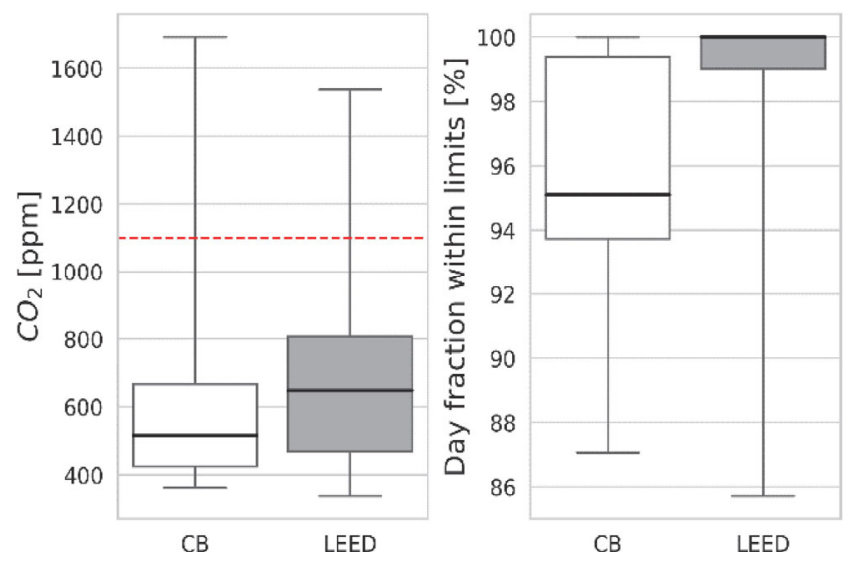

Fig. $5 \mathrm{CO}_{2}$ concentration according to building type using continuous measurements filtered to occupied hours [09:00, 17:00] between July 2017 and February 2019-see Section 4.1; sample size conventional: 3223 hours in 5 buildings; sample size in LEED: 1576 hours in 5 buildings; whiskers indicate minimum and maximum readings; dashed line indicates upper acceptable limit at $1100 \mathrm{ppm}$ according to ASHRAE 62.1

effect and occupant behaviour of window opening to deliver fresh air.

\subsection{Thermal conditions and comfort}

Figure 6 compares the self-reported TSVs and the calculated PMVs using Fanger's model in ANSI/ASHRAE 55 (2017) and ISO 7730 (2005) in the CBs and LEED buildings, and Table 6 illustrates the thermal acceptability percentages of TSVs, TPVs and PMVs ${ }^{3}$. In CBs, only $73 \%$ of the TSVs were within $[-1,+1]$, hence failing the $80 \%$ ASHRAE 55 acceptability threshold. This is consistent with the PMV prediction of neutral to slightly warm and $71 \%$ predicted to fall within ISO 7730 recommended PMV range of $[-0.5,+0.5]$.

In LEED buildings, $85 \%$ of TSVs fell within the ASHRAE 55 acceptable comfort zone, which aligns with the PMV prediction of $85 \%$. An analysis of spot measurements of thermal conditions reveals that dry bulb temperature and mean radiant temperature are almost identical (difference of $\left.0.18 \pm 0.36{ }^{\circ} \mathrm{C}, R^{2}=0.97\right)$, this is consistent with other studies in the literature (Walikewitz et al. 2015; Hughes and Natarajan 2019).

We illustrate prevailing indoor conditions in Figure 7 and Figure 8 based on the time series for air temperature and relative humidity obtained with the Raspberry-Pi devices for both CBs and LEED buildings. These alone cannot be used to quantify the percentage of time that

\footnotetext{
3 Note TSV and TPV are ordinal due to survey design whereas PMV is continuous within the range. Hence, observations will refer to integer values whereas predictions and standards may contain non-integer values.
}

indoor environments meet requirements in ASHRAE 55 of PMV votes in the range of $[-0.5,+0.5]$, because Fanger's model also requires mean radiant temperature, air velocity, occupant clothing and occupant metabolic rate. However, data collected as part of the questionnaires and spot measurements reveal that, besides air and radiant temperatures being almost identical, there is little variation in observed values for air velocity, clothing and metabolic rates. Considering that spot measurements were taken at different times of the year, a reasonable assumption can be made that these values are representative over the continuous measurement periods. Hence, we can estimate the percentage of occupied hours indoor thermal conditions are within the recommended ASHRAE 55 ranges using the mean and standard deviation of these variables. We estimate that between $1 \%$ and $36 \%$ of the data points in the CBs (Figure 7) fall within the ASHRAE 55 recommended range during working hours, in contrast to the range between $49 \%$ and $69 \%$ for the LEED buildings (Figure 8). Despite the uncertainty in the ranges obtained, this suggests better standard compliance in the LEED buildings.

\subsection{Occupants' satisfaction of IEQ}

Figure 9 shows the median, first and third quartile of occupant satisfaction with the LEED and CBs in four IEQ aspects: IAQ and ventilation, noise, lighting, and thermal comfort. Surprisingly, this suggests that the occupants of LEED buildings had a lower median score of satisfaction for all investigated IEQ parameters except noise. This finding was supported with the results of the Kruskal-Wallis $H$ test, which suggests rejecting the null hypothesis of no difference between median response according to the building type for the IAQ and ventilation, noise and thermal comfort ( $p$-value $<0.05)$, while it fails to reject differences for lighting (Table 7).

Further, differences between the median scores of satisfaction achieved for eight individual aspects related to the IEQ were investigated (Table 7 and Figure 10). Interestingly, occupants in LEED buildings had lower satisfaction compared to their counterparts in CBs in overall IAQ, fresh air, ventilation, sun glare, and air temperature where the differences in the median scores of occupants' votes on 7 -point scale were $(2,1,1,1,1)$ respectively. LEED buildings' occupants were more satisfied with the noise levels with a difference in median scores of -1 , similar to Liang et al. (2014). To compare the obtained results to other studies' findings, the differences in mean scores of occupants' satisfaction towards the investigated IEQ parameters were computed. The obtained mean differences ranged between 0.22 and 0.60 and can be considered high when compared it to the literature. For example, Altomonte and Schiavon 

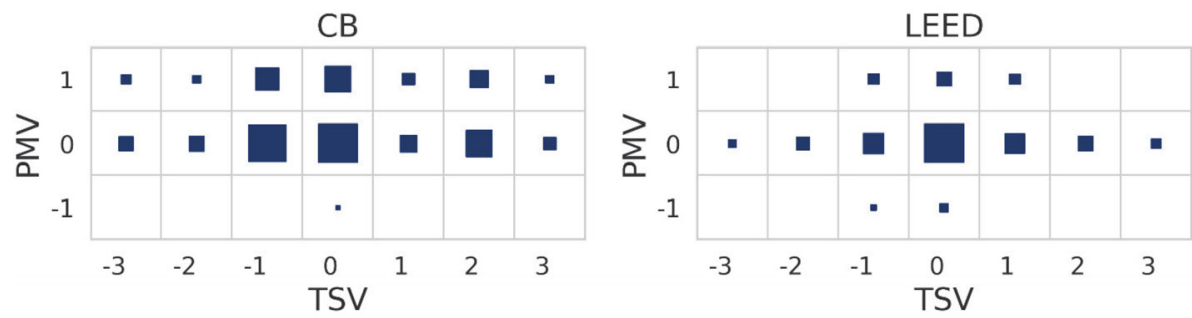

Fig. 6 Comparison of TSV as reported by occupants and PMV as predicted by Fanger model in ISO 7730 (2005). PMV data calculated using spot measurements. The plot shows squares proportional to the number of vote counts only used categories, which vary according to building type. Cases without votes are empty; conventional buildings $\left(\mathrm{CB}, n_{\text {samples }}=241\right.$, minimum count $=1$, maximum count $\left.=57\right)$; $\left(\right.$ LEED, $n_{\text {samples }}=261$, minimum count $=1$, maximum count $=123$ )

Table 6 Thermal acceptability percentage for both subjective and objective measurements; CB indicates conventional building. PMV calculated from spot measurements. Note that the standard specifies a comfort range for PMV $[-0.5,+0.5]$, whereas survey data are ordinal and are hence presented within $[-1,+1]$. For comparison, we present PMV data within both ranges

\begin{tabular}{ccccccc}
\hline Building type & TSV $(\mathrm{M} \pm \mathrm{SD})$ & $\mathrm{PMV}(\mathrm{M} \pm \mathrm{SD})$ & $-1 \leq \mathrm{TSV} \leq+1$ & $-0.5 \leq \mathrm{PMV} \leq+0.5$ & $-1 \leq \mathrm{PMV} \leq+1$ & $-1 \leq \mathrm{TPV} \leq+1$ \\
\hline CBs & $-0.1 \pm 1.3$ & $0.3 \pm 0.4$ & $73 \%$ & $71 \%$ & $95 \%$ & $88 \%$ \\
LEED & $0.0 \pm 1.0$ & $0.3 \pm 0.3$ & $85 \%$ & $85 \%$ & $98 \%$ & $88 \%$ \\
\hline
\end{tabular}

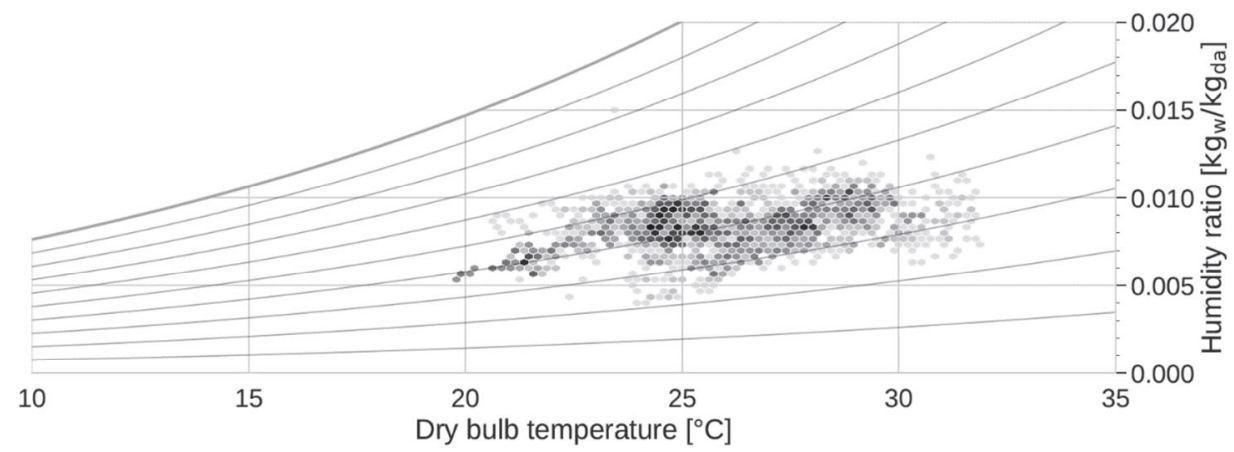

Fig. 7 Psychometric chart for conventional buildings in the study using continuous measurement data filtered to occupied hours [09:00, 17:00] between July 2017 and November 2018-see Section 4.2; sample size of 560 hours in 5 conventional buildings; hexagons shade proportional to number of samples

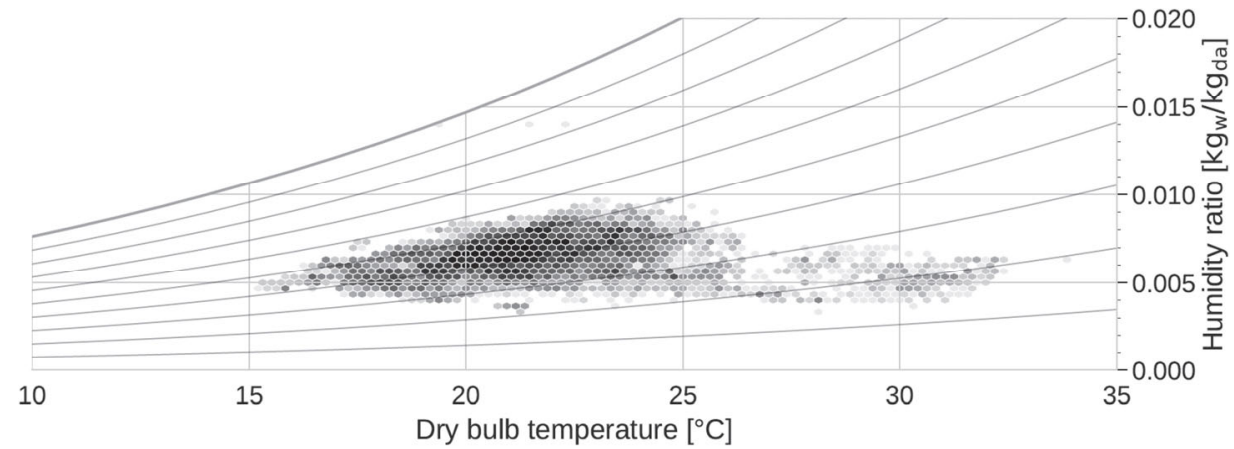

Fig. 8 Psychometric chart for LEED buildings using continuous measurement data filtered to occupied hours [09:00, 17:00] between Jul 2018 and February 2019-see Section 4.2; sample size of 912 hours in 5 LEED buildings; hexagons shade proportional to number of samples

(2013) and Paul and Taylor (2008) report differences in mean scores ranging between 0.001 and 0.22 .

The perceived IEQ results related to thermal comfort show that there are statistically significant differences between CBs and LEED buildings, but that the effect size is moderate
(Table 7). This seems to challenge findings in the previous Section 4.2, where both building types where shown to have satisfactory indoor environments for their occupants based on TSVs, TPVs and PMVs (Table 6). This could be explained considering Figure 10, which shows that the main 


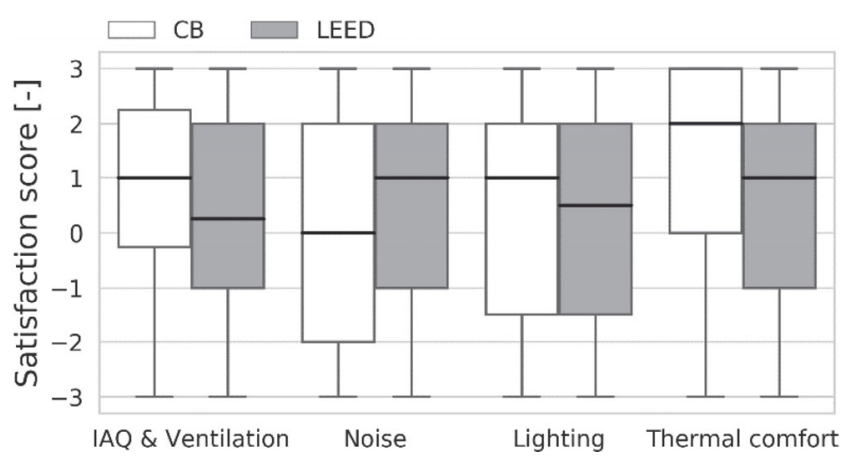

Fig. 9 Occupant satisfaction with four IEQ aspects (sample sizes: 241 respondents in conventional buildings (CB), 261 respondents in LEED buildings; satisfaction score from dissatisfied $(-3)$ to satisfied (3); whiskers indicate minimum and maximum scores)

differences between $\mathrm{CBs}$ and LEED buildings are in the proportion of votes in the extreme categories of the satisfaction scale.

Further, although the ventilation systems in the LEED buildings were designed based on the LEED requirements (8.5 L/(s.person)) and the physical measurements of $\mathrm{CO}_{2}$ showed a compliance with LEED specification (ANSI/ ASHRAE 62.1 2019), surprisingly only $48 \%$ of the respondents were satisfied with the overall IAQ and ventilation compared to $66 \%$ in CBs (Figure 10). One possible explanation reported in the literature that ventilation rates below $10 \mathrm{~L} /(\mathrm{s} \cdot$ person) in buildings can cause lower perceived IAQ (Rashid and Zimring 2008). Ravindu et al. (2015) also show that occupants in a LEED-platinum building in Sri Lanka had lower satisfaction with ventilation compared to the control group.

Figure 11 shows the occupants' responses of which IEQ parameter of the four investigated parameters (IAQ and ventilation, noise, lighting, and indoor air temperature) has a significant negative effect on their work performance. We observe that the percentage of occupants whose work performance was negatively affected by IAQ, noise, and lighting was higher in the LEED buildings compared to

Table 7 Statistical analysis of differences in median statistics from the surveys, according to building type and IEQ aspects ( $H$ indicates Kruskal-Wallis H statistic; ${ }^{*}$ indicates statistically significant results at 95\% confidence level; $\mathrm{RBC}$ is the rank biserial correlation); $\mathrm{CB}$ indicates conventional building. Numbers in the CB and LEED columns represent responses on their respective scales in the survey

\begin{tabular}{|c|c|c|c|c|c|c|}
\hline Case & Reference & $\mathrm{CB}$ & LEED & $H$ & $p$-value & RBC \\
\hline Overall satisfaction & Figure 9 & & & & & \\
\hline IAQ \& Ventilation & & 1 & 0.25 & 14.79 & $<10^{-3 *}$ & -0.20 \\
\hline Noise & & 0 & 1 & 4.68 & 0.03 * & 0.11 \\
\hline Lighting & & 1 & 0.5 & 1.98 & 0.15 & -0.07 \\
\hline Thermal comfort & & 2 & 1 & 12.18 & $<10^{-3 *}$ & -0.18 \\
\hline Individual questions & Figure 10 & & & & & \\
\hline Air quality & & 2 & 0 & 16.78 & $<10^{-3 *}$ & -0.21 \\
\hline Fresh air & & 1 & 0 & 18.29 & $<10^{-3 *}$ & -0.22 \\
\hline Air humidity & & 1 & 1 & 3.44 & 0.06 & -0.09 \\
\hline Overall ventilation & & 1 & 0 & 11.50 & $<10^{-3 *}$ & -0.17 \\
\hline Background noise & & 0 & 1 & 4.68 & 0.03 * & 0.11 \\
\hline Natural light & & 2 & 1 & 0.10 & 0.75 & -0.02 \\
\hline Sun glare & & 1 & 0 & 4.99 & $0.03^{*}$ & -0.11 \\
\hline Air temperature & & 2 & 1 & 12.18 & $<10^{-3 *}$ & -0.18 \\
\hline Work performance & Figure 11 & & & & & \\
\hline Quality of air & & -1 & 0 & 1.68 & 0.19 & 0.07 \\
\hline Distraction from noise & & 0 & 0 & 0.21 & 0.64 & -0.02 \\
\hline Quality of light & & -1 & -1 & 2.21 & 0.14 & 0.08 \\
\hline Temperature & & 0 & 0 & 2.40 & 0.12 & -0.08 \\
\hline Absenteeism & Figure 12 & & & & & \\
\hline Absolute & Eq. (1) & 4 & 0 & 4.22 & 0.04 * & 0.11 \\
\hline Relative & Eq. (2) & 0.02 & 0 & 4.46 & 0.03 * & 0.12 \\
\hline Presenteeism & Figure 13 & & & & & \\
\hline Absolute & Eq. (3) & 80 & 90 & 1.59 & 0.21 & -0.07 \\
\hline Relative & Eq. (4) & 1.14 & 1.13 & 0.25 & 0.62 & 0.03 \\
\hline
\end{tabular}




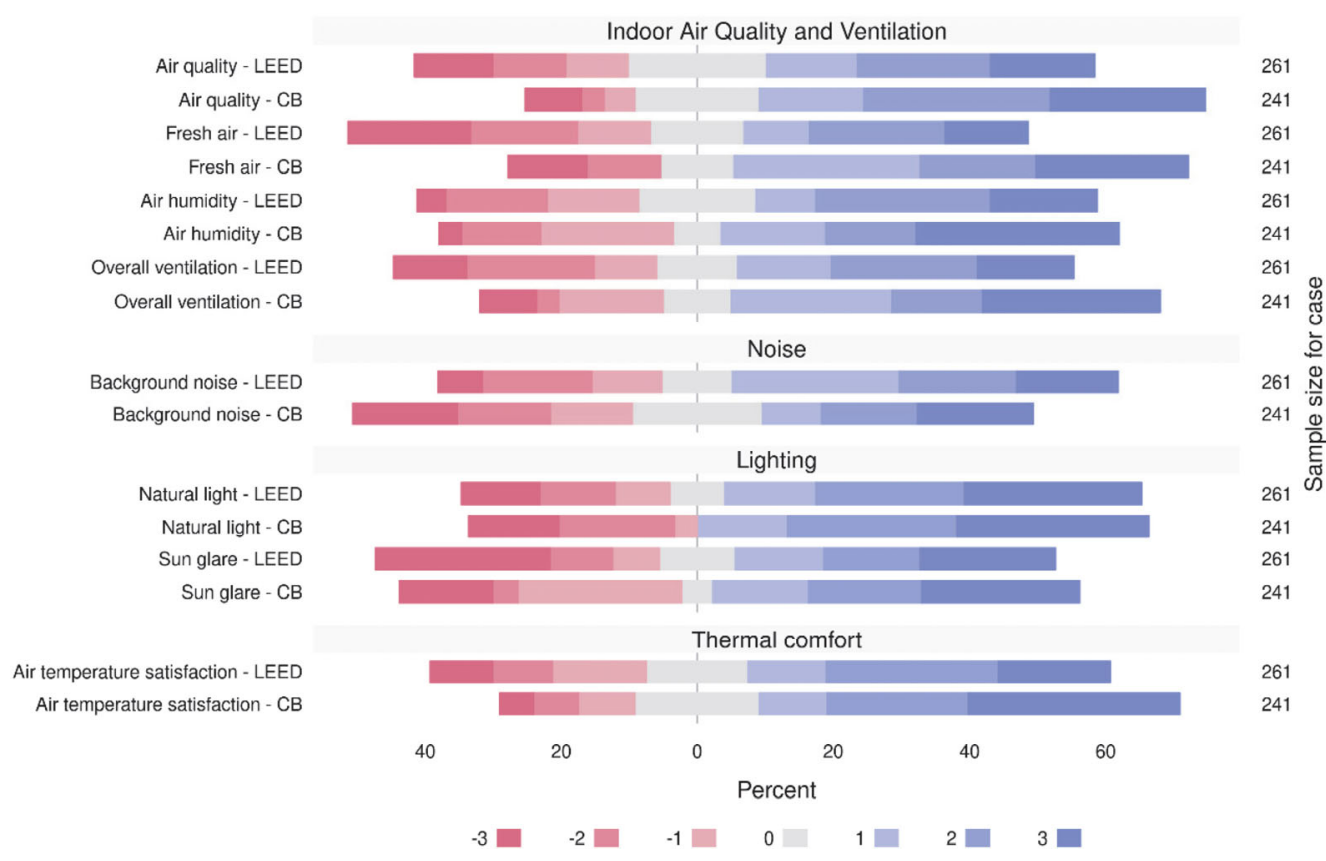

Fig. 10 Occupant satisfaction in IEQ categories according to building type. CB indicates "conventional building", LEED indicates "LEED building"; the scores span from dissatisfied ( -3$)$ to satisfied (3), and ( 0$)$ no opinion. To enable interpretation, the $x$-axis has been mapped such that " $0 \%$ " maps to " 0 " on the survey scale. Numbers on either side of " $0 \%$ " can be used to judge the percentage of responses in each of the three categories below and above " 0 " on the survey scale

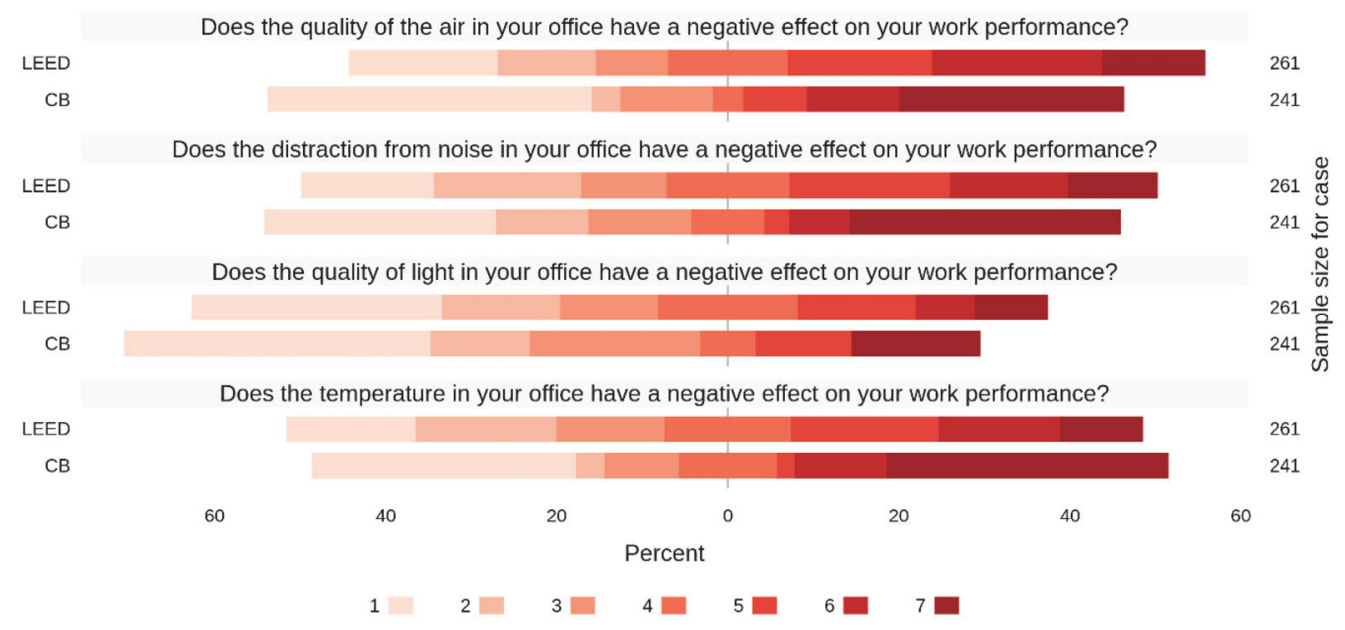

Fig. 11 Effect of four IEQ aspects on occupant work performance. CB indicates “conventional building", LEED indicates "LEED building"; the scores span from not a significant negative effect (1) to a significant negative effect (7), and no opinion (4). To enable interpretation, the $x$-axis has been mapped such that " $0 \%$ " maps to " 4 " on the survey scale. Numbers on either side of " $0 \%$ " can be used to judge the percentage of responses in each of the three categories below and above " 4 " on the survey scale

the CBs, while occupants' work performance in CBs was negatively affected by air temperature. However, this finding was not statistically significant, as the Kruskal-Wallis test fails to reject the null hypothesis of no difference between median responses according to building type for all four aspects ( $p$-value $>0.05$, Table 7 ).

Table 8 shows the results of respondents' perception of the most IEQ parameters that they judged to need improvement. The air temperature was the main concern for $43 \%$ of respondents in CBs, while the ventilation was the major concern for $34 \%$ of respondents in LEED buildings, a finding that is supported across other studies in the literature (Roelofsen 2002; Paul and Taylor 2008). According to $24 \%$ of respondents, the air temperature in LEED buildings needs to be improved. Lighting was seen to need improvement by only $8 \%$ and $12 \%$ of occupants in CBs and LEED respectively, while noise was not perceived as a problem in both buildings types. 
Table 8 Top 5 physical items occupants would like to change in their work places according to the building type (sample sizes: 241 respondents in conventional buildings (CB), 261 respondents in LEED buildings; N.B. multiple choices were allowed per occupantcolumns do not add to $100 \%$ )

\begin{tabular}{clrlr}
\hline Rank & \multicolumn{1}{c}{ CB } & $\%$ & \multicolumn{1}{c}{ LEED } & $\%$ \\
\hline 1 & Air temperature & 43 & Ventilation & 34 \\
2 & Layout & 29 & Nothing & 30 \\
3 & Ventilation & 18 & Temperature & 24 \\
4 & Lighting & 8 & Lighting & 12 \\
5 & Nothing & 8 & Layout & 7 \\
\hline
\end{tabular}

\subsection{Absenteeism and presenteeism}

The 4-week estimation revealed a small difference in the absolute and relative absenteeism of respondents according to the building type (Figure 12), for which the Kruskal-Wallis test suggests rejecting the null hypothesis (Table 7). CBs respondents had 4 hours of absolute absenteeism per month and $0.02 \%$ of relative absenteeism. This is expected to result in a loss of $48 \mathrm{~h}$ of the expected working hours per year, which means losing around $300 \mathrm{JD}(\approx 425$ USD) of annual operation cost due to absenteeism if we consider a yearly income level of about 12,000 JD ( $\approx 16,900$ USD); hence a negligible effect.

Turning now to presenteeism, there is no significant difference in both absolute and relative presenteeism between respondents of LEED and CBs (Figure 13), as the KruskalWallis test fails to reject the null hypothesis (Table 7). Respondents in both building types do not report any lack of performance during time on the job during a 4-week period. The respondents in CBs and LEED buildings rated their work performance at $114 \%$ better than employees working in a similar job to their jobs. This can be understood through the well-known phenomenon of illusory superiority, which is a condition of cognitive bias that refers to the tendency that people overrate their performance above the average or above the performance of other people (Hoorens 1993).

\section{Conclusions}

One of the main unresolved challenges for the building industry is to truly understand how occupants perceive the buildings they occupy, feeding these lessons back into the design and operation process. Although there is a growing database of building use studies, the Middle East is highly under-represented, with no study of IEQ performance in the region. Hence, this is the first study to evaluate the IEQ performance in office buildings in the Middle East. Using Jordan as a representative example of the Middle East, we compare "green" LEED buildings and conventional buildings using post-occupancy evaluation covering: (i) carefully
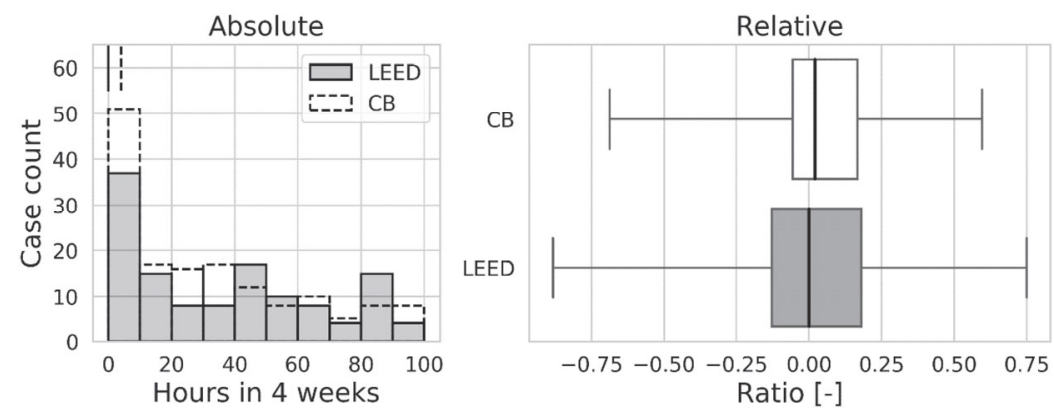

Fig. 12 Absenteeism scores (see Eqs. (1) and (2) for absolute and relative scores, respectively; floating segments indicate group median; positive values indicate absenteeism while negative ones overwork; whiskers indicate minimum and maximum values. Sample sizes: 224 respondents in conventional buildings (CB), 228 respondents in LEED buildings)
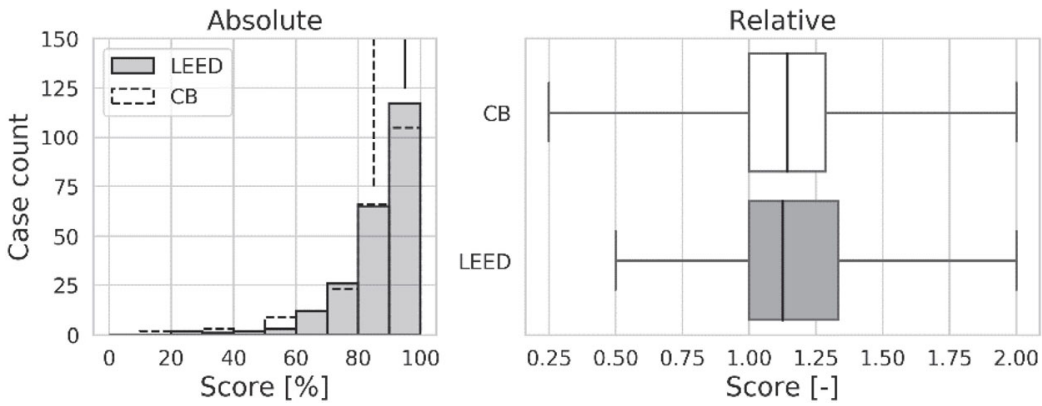

Fig. 13 Presenteeism scores (see Eqs. (3) and (4) for absolute and relative scores, respectively; floating segments indicate group median; boxplot whiskers indicate minimum and maximum values. Sample sizes: 224 respondents in conventional buildings (CB), 228 respondents in LEED buildings) 
constructed bi-lingual surveys, which address occupants' satisfaction of all four IEQ parameters (indoor air quality, noise, lighting, and thermal comfort) (ii) matching objective measurements for air quality and thermal comfort, including high-resolution on-site continuous monitoring of air temperature, relative humidity and $\mathrm{CO}_{2}$ with periodic measurements of mean radiant temperature and air speed. In addition, we assess occupant work performance through absenteeism and presenteeism rates.

We show that the "green" LEED office buildings in Jordan comply with LEED specification in terms of indoor $\mathrm{CO}_{2}$ concentration levels during the monitored period. However, this was contrary to the perception of occupants, who rated the ventilation as the IEQ aspect most in need of improvement. Indeed, the overall IAQ satisfied only $48 \%$ of the occupants in the LEED buildings, whereas it satisfied $66 \%$ of those in the conventional buildings.

In LEED buildings, the estimated percentage of monitored temperature fell within the ASHRAE 55 recommended range during working hours was between $49 \%$ and $69 \%$, while this percentage was lower in CBs (1\%-36\%). Only $73 \%$ of the TSVs were within the ASHRAE 55 acceptable range in CBs, hence failing the $80 \%$ threshold. In LEED buildings, on the other hand, $85 \%$ of TSVs were within the ASHRAE 55 acceptable comfort zone, consistent with the internationally accepted ISO 7730 PMV model, which also suggests a satisfaction rate of $85 \%$, for the same conditions.

A surprising finding was that occupant satisfaction with IEQ aspects namely: overall IAQ, ventilation, fresh air, and sun glare is observed to be greater in the CBs, than in the "green" LEED buildings. Only noise level was perceived to be better in the LEED buildings.

Two out of the four categories of IEQ, i.e. IAQ + ventilation and thermal comfort were seen to be more important issues by the occupants (accounting for $61 \%$ and $58 \%$ of the ranking scores in Table 8 for the CBs and the LEED buildings respectively), while the remaining two, lighting and noise, were seen as much less important ( $8 \%$ and $12 \%$ for CB and LEED respectively in the case of lighting, and $0 \%$ in the case of noise). While we did not objectively verify standards compliance for these aspects, it is reassuring that these aspects were broadly seen as satisfactory by the occupants; with no significant difference in satisfaction with lighting between the buildings types, and slightly better satisfaction in terms of noise in the LEED buildings. Absolute and relative absenteeism was slightly higher in CBs compared to LEED buildings, though with a negligible effect. No differences were reported in relative and absolute presenteeism between buildings types.

According to these results, there are a number of important changes and development, which need to be made in terms of IAQ and ventilation systems in LEED buildings in the region. A periodic assessment of LEED buildings after hand over, which covers the occupants and physical parameters of buildings should be considered to ensure that LEED buildings are not only achieving the specifications of certification but that these standards are in accordance with occupant desires. This is the first study of its kind in the Middle East, which is experiencing significant growth in both the overall number of buildings as well as green buildings. Hence further studies are merited to expand the database of building performance evaluation and help drive the better design of buildings in the region.

Previous version: This paper is an extension of work originally presented in the conference "Indoor Air quality, Ventilation, and Energy Conservation in Buildings" (Elnaklah and Natarajan 2019).

Data Access statement: Data presented in this study are openly available at https://doi.org/10.15125/BATH-00863

\section{Acknowledgements}

The authors would like to thank Mr Mualla for helping with data collection, Dr Nick McCullen for assistance with Raspberry-Pi loggers, and Dr Ian Walker for helping in the design of the questionnaire, and the management of the surveyed buildings for allowing the authors to conduct the study. This work is supported by Al-Ahliyya Amman University in Jordan. D. Fosas reports funding from the UK EPSRC project "The Active Building Centre Research Programme" [EP/V012053/1].

Electronic Supplementary Material (ESM): supplementary material is available in the online version of this article at https://doi.org/10.1007/s12273-020-0695-1.

Open Access: This article is licensed under a Creative Commons Attribution 4.0 International License, which permits use, sharing, adaptation, distribution and reproduction in any medium or format, as long as you give appropriate credit to the original author(s) and the source, provide a link to the Creative Commons licence, and indicate if changes were made.

The images or other third party material in this article are included in the article's Creative Commons licence, unless indicated otherwise in a credit line to the material. If material is not included in the article's Creative Commons licence and your intended use is not permitted by statutory regulation or exceeds the permitted use, you will need to obtain permission directly from the copyright holder.

To view a copy of this licence, visit http://creativecommons.org/licenses/by/4.0/. 


\section{References}

Ali AS, Chua SJL, Lim MelissaEL (2015). The effect of physical environment comfort on employees' performance in office buildings. Structural Survey, 33: 294-308.

Altomonte S, Schiavon S (2013). Occupant satisfaction in LEED and non-LEED certified buildings. Building and Environment, 68: 66-76.

ANSI/ASHRAE 55 (2017). Standard 55-Thermal Environmental Conditions for Human Occupancy. Atlanta: American Society for Heating, Refrigerating and Air Conditioning Engineers.

ANSI/ASHRAE 62.1 (2019). Standard 62.1-Ventilation for Acceptable Indoor Air Quality. Atlanta: American Society of Heating, Refrigerating and Air-Conditioning Engineers.

Armitage L, Murugan A, Kato H (2011). Green offices in Australia: A user perception survey. Journal of Corporate Real Estate, 13: 169-180.

ASTM D6245-18 (2018). Standard Guide for Using Indoor Carbon Dioxide Concentrations to Evaluate Indoor Air Quality and Ventilation. West Conshohocken, USA: ASTM International.

BREEAM (2019). Building Research Establishment Environmental Assessment Method. Available at https://www.breeam.com/. Accessed 30 Nov 2019.

Brown Z, Cole RJ (2009). Influence of occupants' knowledge on comfort expectations and behaviour. Building Research \& Information, 37: 227-245.

Brown Z, Cole RJ, Robinson J, Dowlatabadi H (2010). Evaluating user experience in green buildings in relation to workplace culture and context. Facilities, 28: 225-238.

BUS (2019). Building Use Studies. Usable Buildings. Available at https://www.usablebuildings.co.uk/. Accessed 1 Nov 2019.

CBE (2019). Center for the Built Environment. Available at https:// cbe.berkeley.edu/resources/occupant-survey/. Accessed 3 Nov 2019.

CDC (2020). The National Institute for Occupational Safety and Health (NIOSH), Workplace Safety \& Health Topics. Available at https://www.cdc.gov/niosh/topics/indoorenv/buildingventilation .html. Accessed 16 Jun 2020.

CEN ISO/TR 52000-2 (2017). Energy Performance of BuildingsOverarching EPB Assessment. British Standards Institution.

Christiansen B, Chandan HC (2017). Handbook of Research on Human Factors in Contemporary Workforce Development. Hershey, PA, USA: IGI Global.

Chua SJL, Ali AS, Lim MEL (2016). Physical environment comfort impacts on office employee's performance. MATEC Web of Conferences, 66: 00124.

CIBSE (2019). TM22: Energy Assessment and Reporting Methodology. Available at https://www.cibse.org. Accessed 25 Oct 2019.

Cohen J (1988). Statistical Power Analysis for the Behavioral Sciences, 2nd edn. New York: Lawrence Erlbaum Associates.

Collinge WO, Landis AE, Jones AK, Schaefer LA, Bilec MM (2014). Productivity metrics in dynamic LCA for whole buildings: Using a post-occupancy evaluation of energy and indoor environmental quality tradeoffs. Building and Environment, 82: 339-348.

Cureton EE (1958). The definition and estimation of test reliability. Educational and Psychological Measurement, 18: 715-738.
d'Ambrosio Alfano FR, Olesen BW, Palella BI, Pepe D, Riccio G (2020). Fifty years of PMV model: Reliability, implementation and design of software for its calculation. Atmosphere, 11: 49.

Davies M, Oreszczyn T (2012). The unintended consequences of decarbonising the built environment: A UK case study. Energy and Buildings, 46: 80-85.

Delta OHM (2019). HD32.3-WBGT, PMW, PPD measurement. Available at https://www.deltaohm.com/en/product/hd32-3-wbgtpmw-ppd-measurement/. Accessed 2 Oct 2019.

DODGE (2018). World Green Building Trends. Bedford. Available at http://www.construction.com/products/dodge-research-analytics. Accessed 15 Jun 2020.

Dole C, Schroeder RG (2001). The impact of various factors on the personality, job satisfaction and turnover intentions of professional accountants. Managerial Auditing Journal, 16: 234-245.

DOS (2016). Jordan Statistical Yearbook. Department of Statistics, Jordan. Available at http://www.dos.gov.jo. Accessed 30 Sep 2019.

Elnaklah R (2020). Dataset for "Indoor environment quality and work performance in 'green' office buildings in the Middle East". Bath: University of Bath Research Data. https://doi.org/10.15125/ BATH-00863.

Elnaklah RA, Natarajan S (2019). A comparison of indoor air quality and employee absenteeism in 'local' and 'imported' green building standards. In: IOP Conference Series: Materials Science and Engineering, 609: 042089.

EN ISO 3382-3 (2012). Acoustics-Measurement of Room Acoustic Parameters. Part 3: Open plan offices. British Standard Institution.

EN ISO 52003-1 (2017). Energy Performance of Buildings-Indicators, Requirements, Ratings and Certificates. British Standard Institution.

EN ISO 7726 (2001). Ergonomics of the Thermal EnvironmentInstruments for Measuring Physical Quantities. British Standard Institution.

EN ISO 8996 (2004). Ergonomics of the Thermal EnvironmentDetermination of Metabolic Rate. British Standard Institution.

EN ISO 9920 (2007). Ergonomics of the Thermal EnvironmentEstimation of the Thermal Insulation and Evaporative Resistance of a Clothing Ensemble. British Standard Institution.

EPA (2019). United States Environmental Protection Agency. Available at https://www.epa.gov/. Accessed 3 Oct 2019.

European Parliament (2010). Directive 2010/31/EU of the European Parliament and of the Council of 19 May 2010 on the energy performance of buildings. European Union: Official Journal of the European Union.

European Parliament (2018). Directive (EU) 2018/844 of the European parliament and of the council of 30 May 2018 amending directive 2010/31/EU on the energy performance of buildings and directive 2012/27/EU on energy efficiency. European Union: Official Journal of the European Union.

Federspiel CC, Fisk WJ, Price PN, Liu G, Faulkner D, et al. (2004). Worker performance and ventilation in a call center: analyses of work performance data for registered nurses. Indoor Air, 14: 41-50.

Fostervold KI, Nersveen J (2008). Proportions of direct and indirect indoor lighting-The effect on health, well-being and cognitive performance of office workers. Lighting Research \& Technology, 40: $175-200$.

Garland R (1991). The mid-point on a rating scale: Is it desirable. Marketing Bulletin, 2: 66-70. 
Gobbi S, Puglisi V, Ciaramella A (2016). A rating system for integrating building performance tools in developing countries. Energy Procedia, 96: 333-344.

Gou Z, Lau S (2013). Post-occupancy evaluation of the thermal environment in a green building. Facilities, 31:357-371.

Gou Z, Prasad D, Lau S (2013). Are green buildings more satisfactory and comfortable? Habitat International, 39: 156-161.

Gou Z, Prasad D, Lau S (2014). Impacts of green certifications, ventilation and office types on occupant satisfaction with indoor environmental quality. Architectural Science Review, 57: 196-206.

Hassouneh K, Al-Salaymeh A, Qoussous J (2015). Energy audit, an approach to apply the concept of green building for a building in Jordan. Sustainable Cities and Society, 14: 456-462.

Hedge A, Sakr W, Agarwal A (2005). Thermal effects on office productivity. Proceedings of the Human Factors and Ergonomics Society Annual Meeting, 49: 823-827.

Heiberger RM, Robbins NB (2014). Design of diverging stacked bar charts for likert scales and other applications. Journal of Statistical Software, 57(5): 1-32.

Hoorens V (1993). Self-enhancement and superiority biases in social comparison. European Review of Social Psychology, 4: 113-139.

Al Horr Y, Arif M, Kaushik A, Mazroei A, Katafygiotou M, et al. (2016). Occupant productivity and office indoor environment quality: A review of the literature. Building and Environment, 105: 369-389.

Hughes C, Natarajan S (2019). Summer thermal comfort and overheating in the elderly. Building Services Engineering Research and Technology, 40: 426-445.

IAQMG (2019). A Guide on Indoor Air Quality Certificatin Scheme for Officies and Public Places. Available at https://www.iaq.gov.hk/ media/65346/new-iaq-guide_eng.pdf. Accessed 15 Jun 2020.

IEA (2013). Transition to Sustainable Buildings: Strategies And Opportunities to 2050. Available at https://www.iea.org/newsroom/ news/2013/. Accessed 5 Oct 2019.

IEA (2019). $\mathrm{CO}_{2}$ Emissions from Fuel Combustion 2019. Available at https://webstore.iea.org/co2-emissions-from-fuel-combustion-2019. Accessed 5 Oct 2019.

IFC (2017). Measuring Call Center Performance Global Best Practices. International Finance Corporation. Available at https:// www.ifc.org/wps/wcm/connect/75ce96004cf85d4f8752c7f81 ee63 1cc. Accessed 13 Jun 2020.

ISO 10551 (2019). Ergonomics of the Thermal EnvironmentAssessment of the Influence of the Thermal Environment Using Subjective Judgement Scales. British Standard Institution.

ISO 16814 (2008). Building Environment Design-Indoor Air QualityMethods of Expressing the Quality of Indoor Air for Human Occupancy. British Standard Institution.

ISO 16817 (2017). Building Environment Design-Indoor Environment-Design Process for the Visual Environment. British Standard Institution.

ISO 17772-1 (2017). Energy Performance of Buildings-Indoor Environmental Quality. British Standards Institution.

ISO 7730 (2005). Ergonomics of the thermal environment-Analytical determination and interpretation of thermal comfort using calculation of the PMV and PPD indices and local thermal comfort criteria. Geneva: International Standardization Organization.

JGBC (2018). Your Green Building Guide in Jordan Booklet. Available at https://jordangbc.org. Accessed 1 Oct 2019.
Kessler R, Petukhova M, McInnes K (2007). Short WHO HPQ Absenteesim and Presenteeism Questionnaire. Available at https:// www.hcp.med.harvard.edu/hpq/ftpdir/absenteeism presenteeism scoring 050107.pdf. Accessed 15 Jun 2020.

Komendantova N, Irshaid J, Marashdeh L, Al-Salaymeh A, Ekenberg L, et al. (2017). Middle East North Africa Sustainable Electricity Trajectories Energy Pathways for Sustainable Development in the MENA Region. Available at https://menaselect.info/uploads/ countries/jordan/Country_Fact_Sheet_Jordan.pdf. Accessed 16 Jun 2020.

de Kort Y, Smolders K (2010). Effects of dynamic lighting on office workers: First results of a field study with monthly alternating settings. Lighting Research \& Technology, 42: 345-360.

de Korte EM, Spiekman M, Hoes-van Oeffelen L, van der Zande B, Vissenberg G, et al. (2015). Personal environmental control: Effects of pre-set conditions for heating and lighting on personal settings, task performance and comfort experience. Building and Environment, 86: 166-176.

Lan L, Lian Z (2009). Use of neurobehavioral tests to evaluate the effects of indoor environment quality on productivity. Building and Environment, 44: 2208-2217.

Leaman A (1995). Dissatisfaction and office productivity. Facilities, 13: $13-19$.

Leaman A, Bordass B (2007). Are users more tolerant of 'green' buildings? Building Research \& Information, 35: 662-673.

Liang H-H, Chen C, Hwang RL, Shih WM, Lo SC, Liao HY (2014). Satisfaction of occupants toward indoor environment quality of certified green office buildings in Taiwan. Building and Environment, 72: 232-242.

Lovett T, Lee J, Gabe-Thomas E, Natarajan S, Brown M, et al. (2016). Designing sensor sets for capturing energy events in buildings. Building and Environment, 110: 11-22.

MacNaughton P, Spengler J, Vallarino J, Santanam S, Satish U, et al. (2016). Environmental perceptions and health before and after relocation to a green building. Building and Environment, 104: 138-144.

Maula H, Hongisto V, Östman L, Haapakangas A, Koskela H, et al. (2016). The effect of slightly warm temperature on work performance and comfort in open-plan offices - a laboratory study. Indoor Air, 26: 286-297.

McKinney W (2010). Data structures for statistical computing in Python. In: Proceedings of the 9th Python in Science Conference, Austin, TX. USA.

Menadue V, Soebarto V, Williamson T (2014). Perceived and actual thermal conditions: case studies of green-rated and conventional office buildings in the City of Adelaide. Architectural Science Review, 57: 303-319.

Miller S (1984). Experimental Design and Statistics, 2nd edn. London: Routledge.

Milton DK, Glencross PM, Walters MD (2000). Risk of sick leave associated with outdoor air supply rate, humidification, and occupant complaints. Indoor Air, 10: 212-221.

Nematollahi O, Hoghooghi H, Rasti M, Sedaghat A (2016). Energy demands and renewable energy resources in the Middle East. Renewable and Sustainable Energy Reviews, 54: 1172-1181.

Newsham GR, Birt BJ, Arsenault C, Thompson AJL, Veitch JA, et al. (2013). Do 'green' buildings have better indoor environments? New evidence. Building Research \& Information, 41: 415-434. 
Nishihara N, Yamamoto Y, Tanabe S (2002). Effect of thermal environment on productivity evaluated by task performances, fatigue feelings and cerebral blood oxygenation changes. In: Proceedings of Indoor Air Conference.

Oliphant T (2006). A guide to NumPy. Available at https://numpy.org/. Accessed 10 Jun 2020.

Oxford Brookes University (2019). Brookes Electronic Practice Assessment Document, BePAD. Available at https://bepad.org.uk/. Accessed 15 Oct 2019.

Paul WL, Taylor PA (2008). A comparison of occupant comfort and satisfaction between a green building and a conventional building. Building and Environment, 43: 1858-1870.

Pei Z, Lin B, Liu Y, Zhu Y (2015). Comparative study on the indoor environment quality of green office buildings in China with a long-term field measurement and investigation. Building and Environment, 84: 80-88.

Pournik O, Ghalichi L, Tehrani Yazdi AR, Tabatabaee Jabali SM, Ghaffari M, et al. (2012). Reliability and validity of Persian version of World Health Organization Health and Work Performance Questionnaire in Iranian health care workers. International Journal of Occupational and Environmental Medicine, 3(1): 33-38.

Python Software Foundation (2020). The Python Language Reference. Available at https://docs.python.org/3/reference/. Accessed 10 Jun 2020

R Core Team (2019). R: A Language and Environment for Statistical Computing. Vienna, Austria: R Foundation for Statistical Computing. Available at https://www.r-project.org/. Accessed 2 Jun 2020.

Rashid M, Zimring C (2008). A review of the empirical literature on the relationships between indoor environment and stress in health care and office settings. Environment and Behavior, 40: 151-190.

Ravindu S, Rameezdeen R, Zuo J, Zhou Z, Chandratilake R (2015). Indoor environment quality of green buildings: Case study of an LEED platinum certified factory in a warm humid tropical climate. Building and Environment, 84: 105-113.

Roelofsen P (2002). The impact of office environments on employee performance: The design of the workplace as a strategy for productivity enhancement. Journal of Facilities Management, 1: 247-264.

Sediso BG, Lee MS (2016). Indoor environmental quality in Korean green building certification criteria-certified office buildingsoccupant satisfaction and performance. Science and Technology for the Built Environment, 22: 606-618.

Singh A, Syal M, Grady SC, Korkmaz S (2010). Effects of green buildings on employee health and productivity. American Journal of Public Health, 100: 1665-1668.

Srebric J (2010). Opportunities for Green Building (GB) Rating Systems to Improve Indoor Air Quality Credits and to Address Changing Climatic Conditions. Washington. Available at http://epa.gov/ iedweb00/pdfs/jelena_draft_paper_11-4-10.pdf. Accessed 3 Nov 2020.

Tanabe SI, Haneda M, Nishihara N (2015). Workplace productivity and individual thermal satisfaction. Building and Environment, 91: 42-50.

Tham KW, Wargocki P, Tan Y (2015). Indoor environmental quality, occupant perception, prevalence of sick building syndrome symptoms, and sick leave in a Green Mark Platinum-rated versus a non-Green Mark-rated building: A case study. Science and Technology for the Built Environment, 21: 35-44.

Thatcher A, Milner K (2012). The impact of a 'green' building on employees' physical and psychological wellbeing. Work, 41: 3816-3823.

Thatcher A, Milner K (2016). Is a green building really better for building occupants? A longitudinal evaluation. Building and Environment, 108: 194-206.

Thomas LE (2010). Evaluating design strategies, performance and occupant satisfaction: a low carbon office refurbishment. Building Research \& Information, 38: 610-624.

UNFCCC (1998). Kyoto Protocol to The United Nations Framework Convention on Climate Change. United Nation.

USGBC (2019). LEED (The Leadership in Energy and Environmental Design) Green Building Rating System. Available at http:// www.usgbc.org. Accessed 2 Oct 2019.

Vallat R (2018). Pingouin: statistics in Python. Journal of Open Source Software, 3: 1026.

Veitch JA, Charles KE, Farley KMJ, Newsham GR (2007). A model of satisfaction with open-plan office conditions: COPE field findings. Journal of Environmental Psychology, 27: 177-189.

Vellei M, Natarajan S, Biri B, Padget J, Walker I (2016). The effect of real-time context-aware feedback on occupants' heating behaviour and thermal adaptation. Energy and Buildings, 123: 179-191.

Walikewitz N, Jänicke B, Langner M, Meier F, Endlicher W (2015). The difference between the mean radiant temperature and the air temperature within indoor environments: A case study during summer conditions. Building and Environment, 84: 151-161.

van der Walt S, Colbert SC, Varoquaux G (2011). The NumPy array: A structure for efficient numerical computation. Computing in Science \& Engineering, 13: 22-30.

Wargocki P, Wyon DP, Baik YK, Clausen G, Fanger PO (1999). Perceived air quality, sick building syndrome (SBS) symptoms and productivity in an office with two different pollution loads. Indoor Air, 9: 165-179.

Wei W, Ramalho O, Mandin C (2015). Indoor air quality requirements in green building certifications. Building and Environment, 92: $10-19$.

WGBC (2016). Building the Business Case: Health, Wellbeing and Productivity in Green Offices. World Green Building Council. Available at https://www.worldgbc.org/sites/default/files/WGBC_ BtBC_Dec2016_Digital_Low-MAY24_0.pdf. Accessed 4 Jun 2020.

WGBC (2017). Health, Wellbeing \& Productivity in Offices: The next chapter for green building. UK Green Building Council. Available at https://www.ukgbc.org/ukgbc-work/health-wellbeingproductivity-offices-next-chapter-green-building/. Accessed 14 Jun 2020.

Wickham H, Averick M, Bryan J, Chang W, McGowan LD, et al. (2019). Welcome to the tidyverse. Journal of Open Source Software, 4(43): 1686.

Witterseh T, Wyon DP, Clausen G (2004). The effects of moderate heat stress and open-plan office noise distraction on SBS symptoms and on the performance of office work. Indoor Air, 14: 30-40.

Yudelson J, Meyer U (2013). The World's Greenest Buildings: Promise Versus Performance in Sustainable Design. New York: Routledge. 